\author{
Universidade de São Paulo \\ Faculdade de Economia, Administração e Contabilidade de \\ Ribeirão Preto \\ Departamento de Economia \\ Programa de Pós-graduação em Economia
}

\title{
Consumo com cartão de crédito: impactos de uma alteração no limite de crédito e na taxa de juros
}

Juliana de Freitas Oliveira Favaro

Orientador: Prof. Dr. Cláudio Lucinda

RIBEIRÃO PRETO 
Prof. Dr. Marco Antonio Zago

Reitor da Universidade de São Paulo

Prof. Dr. Dante Pinheiro Martinelli

Diretor da Faculdade de Economia, Administração e Contabilidade de Ribeirão Preto

Prof. Dr. Renato Leite Marcondes

Chefe do Departamento de Economia

Prof. Dr. Cláudio Lucinda

Coordenador do Programa de Pós-graduação em Economia 


\section{JULIANA DE FREITAS OLIVEIRA FAVARO}

Consumo com cartão de crédito: impactos de uma alteração no limite de crédito e na taxa de juros

Dissertação apresentada ao Programa de PósGraduação em Economia - Área: Economia Aplicada da Faculdade de Economia, Administração e Contabilidade de Ribeirão Preto da Universidade de São Paulo, para obtenção do título de Mestre em Ciências. Versão Revisada.

Orientador: Prof. Dr. Cláudio Lucinda

RIBEIRÃO PRETO

2016 
Autorizo a reprodução e divulgação total ou parcial deste trabalho, por qualquer meio convencional ou eletrônico, para fins de estudo e pesquisa, desde que citada a fonte.

Favaro, Juliana de Freitas Oliveira

Consumo com cartão de crédito: impactos de uma alteração no limite de crédito e na taxa de juros/ Juliana de Freitas Oliveira Favaro; Orientador: Prof. Dr. Cláudio Lucinda

RIBEIRÃO PRETO, 2016- 64 p. : il.

Dissertação (Mestrado) - Universidade de São Paulo, 2016.

1. Teoria de Consumo 2. Restrição à crédito 3. Mercado de crédito I. Orientador: Prof. Dr. Cláudio Lucinda II. Universidade de São Paulo - USP Ribeirão Preto. III. Faculdade de Economia Administração e Contabilidade. IV. Consumo com cartão de crédito: impacto de uma alteração no limite de crédito e na taxa de juros 
Nome: FAVARO, Juliana de Freitas Oliveira

Título: Consumo com cartão de crédito: impactos de uma alteração no limite de crédito e na taxa de juros

Dissertação apresentada ao Programa de PósGraduação em Economia - Área: Economia Aplicada da Faculdade de Economia, Administração e Contabilidade de Ribeirão Preto da Universidade de São Paulo, para obtenção do título de Mestre em Ciências. Versão Revisada.

Aprovada em

Banca Examinadora

Prof. Dr. Bruno Cesar Aurichio Ledo FEARP-USP

Prof. Dr. Bruno Ferman

FGV-EESP

Prof. Dr. Klênio Barbosa

FGV-EESP 


\section{Agradecimentos}

Dedido este trabalho aos meus pais que sempre me incentivaram à estudar e deram todo o suporte para que eu chegasse até aqui. Ao meu marido, que me apoio durante todo o período do mestrado, inclusive revisando e discutindo este trabalho comigo. Com certeza este trabalho só saiu porque ele esteve do meu lado.

Agradeço ao meus gestores por terem possibilitado um período de licença para realização das disciplinas do mestrado e pelas discussões e dicas durante o período da dissertação.

E meu muito obrigado ao meu orientador, por ter me orientado mesmo a distância e por ter proporcionado os insumos teóricos para que este trabalho fosse executado. 


\section{Resumo}

FAVARO, J. F. O. Consumo com cartão de crédito: impactos de uma alteração no limite de crédito e na taxa de juros 2016. Dissertação (Mestrado) Faculdade de Economia, Administração e Contabilidade de Ribeirão Preto, Universidade de São Paulo, Ribeirão Preto, 2016.

O avanço no uso do cartão de crédito e sua função como instrumento de crédito afetou o padrão de consumo das famílias. O presente trabalho pretende analisar como alterações no limite de crédito e na taxa de juros do cartão de crédito afetam o consumo. A partir dos resultados obtidos com esta primeira análise, podemos verificar a validade das predições das Teorias de Consumo, como a Teoria de Renda Permanente.

Palavras-chaves:Cartão de Crédito, Teoria de Consumo, Restrição à Crédito 


\begin{abstract}
FAVARO, J. F. O. Credit Card Consumption: Impacts of a credit card limit and an interest rate alterations. 2016. Dissertação (Mestrado) - Faculdade de Economia, Administração e Contabilidade de Ribeirão Preto, Universidade de São Paulo, Ribeirão Preto, 2016.

The advance in the credit card usage and its function as a means of credit affects the consumption of the families. This work intend to analyze how modifications in the limit and interest rate of the credit card affects their consumption. From the results obtained with this first analysis, we may verify the validity of the predictions of the Consumption Theories, as the Permanent Income Theory.
\end{abstract}

Keywords:Credit card, Consumption Theory, Consumption Profile 


\section{Sumário}

Sumário . . . . . . . . . . . . . . . . . . 8

Lista de ilustrações . . . . . . . . . . . . . . . . . 9

Lista de tabelas . . . . . . . . . . . . . . . . . 10

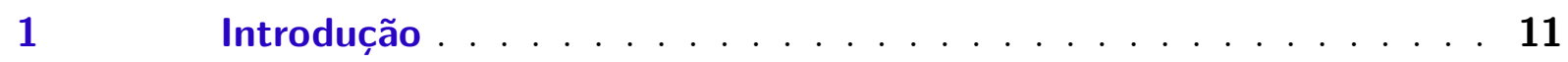

2 Revisão Bibliográfica . . . . . . . . . . . . . . . . . . . 13

$2.1 \quad$ Teoria da renda permanente e buffer stock model . . . . . . . . . . . . . . 19

3 Metodologia e Dados . . . . . . . . . . . . . . . . 20

$3.1 \quad$ Dados . . . . . . . . . . . . . . . . . 20

3.2 Metodologia . . . . . . . . . . . . . . . 24

$4 \quad$ Resultados . . . . . . . . . . . . . . . . . . . . 28

4.1 Efeito da variação do limite de crédito . . . . . . . . . . . . 28

4.2 Efeito da variação da taxa de juros . . . . . . . . . . . . 38

4.3 Heterogeneidade dos efeitos . . . . . . . . . . . . . . 45

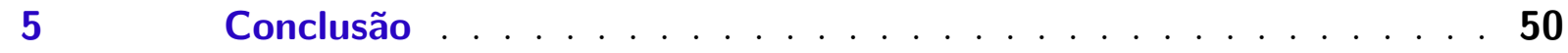

Referências . . . . . . . . . . . . . . . 52 


\section{Lista de ilustrações}

Figura 1 - Efeito de longo prazo dos débitos em relação à variação do limite de crédito conforme incluímos defasagens da variação do limite de crédito. Fonte: Elaborado pelo autor. . . . . . . . . . . . . . . . . . 29

Figura 2 - Efeito de longo prazo dos débitos em relação a variação do limite Alteração automática do limite de crédito. Fonte: Elaborado pelo autor. 30

Figura 3 - Efeito de longo prazo dos débitos em relação a variação do limite - Alteração do limite de crédito solicitada pelo cartonista. Fonte: Elaborado pelo autor. . . . . . . . . . . . . . . . . . . 31

Figura 4 - Efeito de longo prazo dos débitos em relação à variação da taxa de juros conforme incluímos defasagens da variação do limite de crédito. Fonte: Elaborado pelo autor.

Figura 5 - Efeito de longo prazo dos débitos em relação à variação da taxa de juros - Cartão com pagamento. Fonte: Elaborado pelo autor. . . . . . . . . . 40

Figura 6 - Efeito de longo prazo dos débitos em relação à variação da taxa de juros - Cartão sem pagamento. Fonte: Elaborado pelo autor. . . . . . . . . . 40 


\section{Lista de tabelas}

Tabela 1 - Efeito de longo prazo dos débitos em relação a variação do limite Diferentes especificações de estimação. $(*)$ indica efeito de longo prazo signifincante à 5\%. Fonte: Elaborado pelo autor. . . . . . . . . . . . 34

Tabela 2 - Efeito de longo prazo dos débitos em relação a variação do limite Diferentes especificações de estimação - Demais análises. (*) indica efeito de longo prazo signifincante à 5\%. Fonte: Elaborado pelo autor. 37

Tabela 3 - Teste F para os instrumentos. Fonte: Elaborado pelo autor. . . . . . . 37

Tabela 4 - Teste de Hansen. Fonte: Elaborado pelo autor. . . . . . . . . . . . . 37

Tabela 5 - Efeito de longo prazo dos débitos em relação à variação da taxa de juros - Diferentes especificações de estimação. (*) indica efeito de longo prazo signifincante à $5 \%$. Fonte: Elaborado pelo autor. . . . . . . . . . 42

Tabela 6 - Efeito de longo prazo dos débitos em relação à variação da taxa de juros utilizando apenas 6 defasagens da taxa de juros - Diferentes especificações de estimação. $\left(^{*}\right)$ indica efeito de longo prazo signifincante à 5\%. Fonte: Elaborado pelo autor. . . . . . . . . . . . . . . . . . . . . 43

Tabela 7 - Teste F para os instrumentos. Fonte: Elaborado pelo autor. . . . . . . 44

Tabela 8 - Teste de Hansen. Fonte: Elaborado pelo autor. . . . . . . . . . . . . . 44

Tabela 9 - Heterogeneidade nas estimações do efeito de longo prazo de alterações do limite nas alterações dos débitos. $\left(^{*}\right)$ indica efeito de longo prazo signifincante à $5 \%$. Fonte: Elaborado pelo autor. $\mathrm{O} *$ indica que não foi possível estimar a matriz de variância e covariância dos parâmetros. 48

Tabela 10 - Heterogeneidade nas estimações do efeito de longo prazo de alterações da taxa de juros nas alterações dos débitos. (*) indica efeito de longo prazo signifincante à $5 \%$. Fonte: Elaborado pelo autor. . . . . . . . . . 49 


\section{Introdução}

Utilizando informações do comportamento dos indivíduos que possuem cartão de crédito podemos analisar como o mercado de crédito afeta o comportamento de consumo dos indivíduos. Neste contexto, este trabalho pretende estudar como o valor do limite de crédito e a taxa de juros do cartão de crédito afetam as decisões de consumo e endividamento das famílias. Nesta linha, ainda é possível analisar como as teorias de consumo, tais como Teoria da Renda Permanente, Restrição à crédito ${ }^{1}$ se aplicam no contexto do consumidor brasileiro. Para este trabalho, utilizaremos uma base de dados representativa dos portadores de cartão de crédito no Brasil contendo informações dos valores gastos, limite de crédito, taxa de juros, além de informações de controle como informações cadastrais dos portadores destes cartões e escore de crédito.

Este trabalho seguirá os passos de Gross e Souleles (2001a), buscando verificar se os efeitos encontrado neste trabalho da variação da taxa de juros e do limite de crédito nos débitos no cartão de crédito também ocorrem no Brasil. O trabalho de Hochguertel, Weber e Alessie (2005) mostra que o efeito do limite de crédito e da taxa de juros podem ser diferentes dependendo do desenvolvimento econômico observado em cada região ou país. Este mesmo argumento se mostra presente em Lucinda e Vieira (2014), que ainda ressalta as diferenças no amadurecimento do mercado de crédito no Brasil, muito defasado em termos de instituições e informações dos clientes em relação ao EUA.

Testar como o consumo se comporta em relação uma alteração do limite de crédito colabora para o desenvolvimento da teoria econômica. Uma vez que o consumo no cartão de crédito se torna cada vez mais representativo do consumo total das famílias, podemos usar o comportamento no cartão de crédito para comparar a predição dos modelos de teoria do consumo com a realidade. Entendendo como os indivíduos se comportam em relação ao cartão de crédito, contribuímos também para que as instituições financeiras adequem a oferta deste produto, melhorem a precificação, que é dada principalmente pela taxa de juros, e evitem perdas financeiras.

\footnotetext{
$\overline{1}$ Iremos explorar estas teorias na seção seguinte.
} 
O fato de não ser necessário carregar dinheiro fazendo-se uso do cartão de crédito trás benefícios tanto pela facilidade quanto pela segurança. As vantagens desta forma de pagamento fez com que $78 \%$ das famílias americanas tivessem pelo menos 1 cartão de crédito (CARDHUB.COM, 2014). Em 2011, nos USA, 66\% das compras das famílias foram feitas usando pagamento via cartão, sendo $29 \%$ cartão de crédito (The Huffington Post , 2014).

Em 2013, no Brasil, 76,1\% da população possuía cartão de débito e/ou crédito (Associacao Brasileira das Empresas de Cartoes de Credito e Servicos, 2014). O volume transacionado foi de $\mathrm{R} \$ 853$ milhões, sendo $\mathrm{R} \$ 553$ milhões no cartão de crédito. Levando em consideração aqueles que possuem um meio eletrônico de pagamento, a participação dos cartões de débito e crédito no total de gastos atinge $57 \%$ do consumo das famílias.

O cartão de crédito fornece um limite de crédito para seu possuidor, que efetua compras até alcançar este limite. O valor das compras é acumulado gerando a fatura do cartão emitida uma vez ao mês para ser paga pelo cartonista. Porém, em 2013, 31\% da população brasileira já deixara de efetuar o pagamento da fatura integral ou pagou o valor mínimo, $15 \%$ da fatura (Associacao Brasileira das Empresas de Cartoes de Credito e Servicos, 2014). O saldo não pago fica acumulado consumindo o limite de crédito do cartão e sobre este é contabilizado juros. Note que é possível utilizar o cartão de crédito como uma forma de financiamento (compro hoje e pago depois) e também como forma de crédito (compro hoje, pago uma parte da fatura e acumulo o resto para pagar depois).

Sendo uma forma de financiamento, o cartão de crédito influencia na dinâmica de endividamento das pessoas. Segundo pesquisa da CNC (Divisão Econômica da Confederação Nacional do Comércio de Bens, Serviços e Turismo), realizada em 2013, 75,2 \% das famílias endividadas citaram o cartão de crédito como uma das fontes de seu endividamento (ESTADAO.COM, 2014).

Na seção seguinte temos um overview dos principais trabalhos que analisam como o cartão de crédito influencia o padrão de consumo dos indivíduos e o mercado de crédito. Na seção 2 descrevemos os dados e a metodologia que pretendemos utilizar para estudar como o mercado de crédito afeta o comportamento de consumo dos individuo. Na seção 4 
temos os resultados e na seção 5 as principais conclusões do estudo.

\section{Revisão Bibliográfica}

Há muitos trabalho na literatura que estudam o efeito do cartão de crédito na economia. Aqui focaremos naqueles que relacionam o cartão de crédito como forma de crédito para seu possuidor e o quanto esta função modifica o comportamento de consumo do cartonista.

O cartão de crédito pode funcionar como uma linha de crédito para seu possuidor por permitir que seu consumo vá além da renda corrente e que apenas uma parcela do total gastos seja paga, transformando o saldo devedor numa dívida a ser paga na fatura seguinte ou parcelada nas próximas faturas. Assim, a difusão do cartão pode ter alterado o perfil de consumo da população, que passou a ter uma nova linha de crédito disponível para o consumo.Tratando-se de um crédito, uma variável importante é a taxa de juros que define custo de se utilizar o cartão de crédito como forma de financiamento, ou seja, todo o saldo da fatura não pago na data ou em sua totalidade é corrigido até a próxima fatura via taxa de juros determinada no momento da contratação do cartão de crédito. Assim, com a expansão do mercado de cartão de crédito no mundo, o efeito do limite de crédito e da taxa de juros e seu impacto no consumo das famílias se tornou objeto de vários estudos, alguns listados abaixo.

Gross e Souleles (2001a), um dos principais trabalhos nesta área, exploram o efeito da variação do limite de crédito e taxa de juros no saldo não pago, ou seja, nos débitos acumulados, e encontraram que, dado um aumento do limite de crédito, os débitos variam positivamente entre $10 \%$ a 14\%. Em relação à variação da taxa de juros, a elasticidade dos débitos em relação aos juros é de -1,3, levando os autores a concluírem que a demanda por crédito é elástica. Reforça este resultado o trabalho de Hochguertel, Weber e Alessie (2005) que analisa a demanda por crédito na Itália e encontra também uma demanda elástica, sendo que a sensibilidade da demanda em relação à taxa de juros é maior na região Norte do país que na região Sul e Central. Isto, segundo os autores, se deve a 
maior concorrência no setor financeiro na região Norte, que é a mais desenvolvida na Itália. Para o Brasil, Lucinda e Vieira (2014) analisaram a sensibilidade do consumo no cartão de crédito em relação à taxa de juros estudando dois grupos de possuidores de cartões. Para o grupo de mais elevada renda (cerca de USD 20.000), encontraram uma elasticidade de 0,19 , ou seja, para cada aumento de 1 ponto percentual dos juros, uma redução de $0,19 \%$ dos total de débitos pendentes. Já para o segundo grupo, de renda mais baixa (cerca de USD 8.000) não encontraram um efeito bem identificado da taxa de juros do total de débitos acumulados no cartão. Este resultado é condizente com os achados na literatura, que mostram que países em desenvolvimento, como o Brasil, tendem a apresentar inelasticidade da demanda por crédito em relação à taxa de juros, enquanto países desenvolvidos apresentam elevada elasticidade (LUCINDA; VIEIRA, 2014).

A diferença dos resultados de Gross e Souleles (2001a) e Lucinda e Vieira (2014) mostram a importância de se estudar o mercado de crédito de diferentes países. A dinâmica de acesso à crédito entre países desenvolvidos e em desenvolvimento é diferente, tanto pela constituição das instituições e sistema bancário quanto pelo acesso as informações quantitativamente maiores e qualitativamente melhores nos países desenvolvidos além de a estrutura de renda da população e taxa de juros serem diferentes (LUCINDA; VIEIRA, 2014). Assim, o impacto dos determinantes do crédito, neste caso, a taxa de juros praticadas no cartão de crédito, pode ser diferente entre os estudos.

Sobre o efeito da taxa de juros, Agarwal et al. (2006) encontram que ao decidir entre duas propostas de cartão de crédito, uma com taxa de juros alta mas sem anuidade e outra com anuidade e baixa taxa de juros, cerca de $40 \%$ dos indivíduos fazem uma má escolha. Estes cartonistas, ou optam por um cartão de crédito com a taxa de juros mais alta entre as opções e utilizam-no como forma de obter crédito ou optam por pagarem anuidade sendo que não utilizarão o cartão de crédito como forma de se financiarem e então não se beneficiam da taxa de juros menor neste contrato.

Na mesma linha de Agarwal et al. (2006), Ponce, Seira e Zamarripa (2014) mostram que $47 \%$ dos indivíduos com dois cartões de créditos considerados idênticos em benefícios alocam suas compras naquele que possui maior taxa de juros e $21 \%$ utilizam o cartão com 
taxa de juros mais alta para se financiarem. Ou seja, estão ou estarão pagando encargos maiores que o necessário caso buscassem minimizar seus custos com taxa e encargos do cartão de crédito. Também encontram que aqueles indivíduos que receberam uma redução da taxa de juros em um dos dois cartões não realocam sua dívida para o cartão que se tornou mais barato, apenas aumentam seus gastos.

Em outro trabalho explorando o efeito da taxa de juros, Stango e Zinman (2013) analisam a dispersão da taxa de juros praticada no EUA. Eles encontram que a diferença observada nas taxa de juros praticadas se deve não só a diferentes perfis de portadores de cartão de crédito, mas também à diferente precificação que os emissores de cartão praticam para um mesmo tipo de cliente e o fato de indivíduos iguais receberem propostas heterogêneas entre si quanto à taxa de juros e outros custos. Ainda em relação à dispersão dos custos de encargos e a taxa de juros do cartão de crédito, os autores argumentam que esta dispersão na taxação tem impacto na dispersão da taxa de poupança, ou seja, argumentam que uma variação negativa na taxa de juros afetaria positivamente a taxa de poupança da população.

Os resultados dos trabalhos acima citados parecem contrários à teoria econômica. Espera-se que um agente racional busque a forma mais barata de se obter crédito. Outra evidência deste comportamento que não parece maximizador de utilidade, Gross e Souleles (2001a) e Telyukova (2013) relatam que há indivíduos que possuem dívida no cartão de crédito e ao mesmo tempo possuem ativos financeiros. Este comportamento parece não se encaixar na ideia de agente racional buscando maximizar seus ganhos uma vez que as taxa de juros pagas pelos débitos no cartão de crédito são geralmente mais altas que a dos ativos financeiros em questão. Estes autores chamam este fenômeno de 'Debt Puzzle'. Uma das justificativas para tal comportamento seria que a retenção de ativos com liquidez se dá por motivos precaucionários, ou seja, ter um dinheiro guardado para alguma emergência (TELYUKOVA, 2013).

Ainda em relação ao comportamento maximizador do indivíduo, Sprenger e Stavins (2008) propõem dois motivos para o acúmulo de débito do cartão de crédito. Um destes motivos seria que mesmo tendo uma das maiores taxas de financiamento do mercado, a 
facilidade na tomada de crédito compensaria os juros elevados. O segundo seria devido ao descontrole financeiro, ou seja, os indivíduos seria incapazes de lidar com o mercado de crédito. Isto, para Ausubel (1991 apud SPRENGER; STAVINS, 2008, p. 5), seria um dos motivos dos elevados lucros do setor de cartão de crédito. Utilizando uma pesquisa de 2005 sobre frequência de uso e benefícios dos meios de pagamento, os autores encontram que indivíduos revolver (aqueles que pagam menos que o total da fatura, mantendo débitos no cartão), tendem a utilizar mais cartão de débito que os demais, pois alegando que não conseguem manter um controle financeiro ao utilizarem o cartão de crédito, o que os levam a acumular saldo acima da sua capacidade de pagamento.

Talvez por ser uma novidade, os indivíduos ainda não aprenderam a utilizar o cartão de crédito da forma mais eficiente. O trabalho de Agarwal et al. (2008) conclui que indivíduos que possuem cartão de crédito há mais tempo tendem a pagar menos tarifas extras, como as de uso acima do limite, pagamento em atraso e saque usando o limite de crédito do cartão. Os autores encontram que o percentual de contas que arcam com estes custos diminuiu de $57 \%$ para $13 \%$ entre contas com 1 e 4 anos de existência. Este trabalho conclui que o efeito de aprendizado no tempo exerce uma influência positiva para otimização de comportamento e indivíduos que pagaram taxa extra este mês tem menor probabilidade de pagá-las novamente no mês seguinte. Porém, mesmo na presença destes dois efeitos, indivíduos que arcaram com custos extras tem $20 \%$ a mais de chance de pagá-las novamente daqui a 2 anos.

As instituições financeiras buscam incentivar o uso do cartão de crédito tanto por ser um produto rentável uma forma de pagamento mais segura e menos custosa que as alternativas. Uma das formas de incentivo são os programas de recompensas que transformam os valores gastos no cartão em pontos que podem ser convertidos em brindes como produtos eletrônicos, passagens aéreas, e outros. Construindo um modelo mensurando a utilidade de cada meio de pagamento, Ching e Hayashi (2010) usam o modelo para testar o quanto a eliminação destes programas de recompensa alteraria o perfil de consumo. Encontram que há uma redução moderada do uso do cartão de crédito, mais este continua sendo um meio vantajoso para os indivíduos mesmo na ausência dos 
programas de recompensas.

A maior procura por cartões de crédito exigiu o desenvolvimento de ferramentas para analisar sua concessão e precificação. Uma das ferramentas utilizadas para precificação dos contratos de cartão de crédito é o escore de crédito. Gross e Souleles (2001b) analisam a eficiência desta ferramenta em prever a taxa de default e mostram que as principais variáveis utilizadas no modelo de escore de crédito (valores das compras e dos pagamentos, atrasos no pagamento, variáveis macroeconômicas como desemprego) explicam apenas uma parte do aumento da taxa de default observada entre o período analisado de 1995 a 1997. Segundo os autores, o aumento das taxas de default e pedidos de falência estaria ligado também à redução de seus custos: judicial, financeiro, moral e também a redução da restrição de acesso a outros créditos no futuro.

Em relação ao perfil de endividamento dos possuidores de cartão de crédito, Jiang e Dunn (2013) analisam uma 'curva de endividamento e pagamento', que apresenta um crescimento no endividamento quando se é jovem, até uma fase adulta onde ocorre o pico de endividamento e após isto a curva apresenta queda. Porém, analisando o endividamento para diferentes gerações, os autores encontram que a gerações mais novas apresentam um endividamento cada vez maior que as anteriores, com taxa de pagamento destas dívidas cada vez menores. Caso este padrão persista poderá haver cada vez mais pessoas endividadas e/ou com dificuldades de quitarem suas dívidas.

Além dos trabalhos sobre uso e endividamento no cartão de crédito, há outros que abordam questões como a precificação do cartão de crédito, dado principalmente pela taxa de juros, uma das mais elevadas entre os produtos financeiros, mesmo sendo o mercado de cartões considerado um mercado competitivo. Para justificar esta constatação, Ausubel (1991 apud SCHOLNICK et al., 2008, p. 1469) abordam a questão da seleção adversa no mercado de crédito ${ }^{2}$ enquanto Stango (2002 apud SCHOLNICK et al., 2008, p. 1470) justificam o débito acumulado no cartão de crédito como uma barreira para a migração de um cartão com taxa mais cara para um novo contrato com taxa mais barata e

2 Observa-se no mercado de crédito que indivíduos que aceitam uma proposta de oferta de crédito, em média, possuem pior risco de default que aqueles que não aceitam, sendo que quanto maior a taxa de juros definida no contrato maior a diferença de risco entre os que aceitam e não aceitam a proposta. 
Vigna e Malmendier (2004 apud SCHOLNICK et al., 2008, p. 1471) abordam o problema do descasamento entre a compra e o pagamento da fatura do cartão e a baixa taxa de desconto intertemporal dos indivíduos como uma justificativa para a manutenção de juros tão elevados no cartão de crédito.

Por meio do uso do cartão de crédito também é possível observar como choques de renda inesperados afetam os indivíduos. Verificando os gastos, variação nos débitos e pagamentos nos cartões de crédito após uma restituição do Imposto de Renda sobre Pessoa Física nos Estados Unidos, em 2001, Agarwal, Liu e Souleles (2007) encontram que inicialmente as pessoas pagam suas dívidas e logo após aumentam o consumo, sendo que $12 \%$ da restituição é gasto com consumo. Este resultado se contrapõe à Teoria da Renda Permanent e uma explicação para o comportamento encontrado por Agarwal, Liu e Souleles (2007) seria a restrição à crédito. O aumento dos gastos é mais acentuado em indivíduos com crédito restrita enquanto nos indivíduos sem restrição observa-se apenas uma redução dos débitos acumulados, indicando que a renda recebida é usada mais para regularização de dívida que aumento de consumo.

Nesta mesma linha, Agarwal e Qian (2013) analisam como um programa de distribuição de renda única do governo de Cingapura afetou todos os gastos e pagamentos dos cingapurianos. Os autores alegam que este é um trabalho possui resultados mais robusto, uma vez que analisa não apenas o cartão de crédito, que pode subestimar o resultado dado que este não representa todo o consumo dos indivíduos e apenas os que não tem restrição de crédito (no caso, ainda tem limite no cartão) poderão responder a este choque de renda. Analisando um horizonte de 10 meses, para cada dólar repassado pelo governo, US\$0,90 viram consumo, sendo que o aumento do consumo se inicia logo após o anúncio do programa, 2 meses antes do dinheiro ser efetivamente transferido para a população. Isto é um resultado que segue a linha da Teoria do Ciclo de Vida, já que os indivíduos responderam não apenas ao recebimento do dinheiro, mas ao anúncio do mesmo. De início os gastos ocorrem no cartão de crédito e após o recebimento, aumentam os gastos com o cartão de débito e há moderado pagamento das dívidas acumuladas anteriormente. Analisando a heterogeneidade dos indivíduos, encontram que aqueles que não possuem 
restrição de crédito, ou seja, ainda possuem limite no cartão, respondem ao choque de renda mais do que aqueles com restrição de crédito.

\subsection{Teoria da renda permanente e buffer stock model}

A Teoria da Renda Permanente descreve que a decisão sobre o montante a ser consumido é intertemporal, ou seja, os indivíduos consideram a renda ao longo da vida e maximizam a utilizadade do consumo em cada período de tempo sujeito a renda total esperada. Umas das consequências desta maximização intertemporal é que o consumo esperado é constante ao longo da vida, sendo suavizado utilizando poupança e tomando empréstimos no mercado.Assim, supõem-se que o acesso a crédito possui a mesma facilidade que o acesso a poupar, ou seja, supõem que não existe restrição de liquidez.

Como o mercado de cartão de crédito é um mercado de crédito, podemos utilizar os dados disponíveis e verificar a existência da restrição de liquidez. Caso um aumento do limite de crédito implique em um aumento dos débitos, podemos sugerir que os indivíduos sofrem de restrição de liquidez. Porém, esperamos que apenas aqueles com alta taxa de utilização do limite de crédito do cartão sofram com restrição de crédito, uma vez que para aqueles que ainda têm limite disponível, ainda há crédito disponível para ser utilizado.

Em Gross e Souleles (2001b), o efeito positivo do aumento do limite de crédito nos débitos foi encontrado tanto para indivíduo considerado com restrição de crédito, que seriam aqueles com alta utilização do limite de crédito do cartão, mas também para aqueles que ainda possuíam uma parcela considerável do limite de crédito disponível para ser tomada como um forma de crédito. Isto evidência não só a presença de restrição de crédito mas também a presença de um outro efeito, denominado como 'buffer stock'. Os trabalhos de Deaton (1989) e Ludvigson (1999) exploram este conceito que traduzindo para o mercado de crédito implicaria que as pessoas tenderiam a manter um volume de crédito disponível por motivos precaucionários. Com o aumento do limite de crédito disponível no cartão, o volume de crédito precaucionário se tornaria maior que o considerado pelas famílias. Desta forma, uma parcela do novo crédito é utilizada para consumo. Isto explicaria o efeito de 
aumento dos débitos, encontrado por Gross e Souleles (2001b), mesmo para indivíduos que possuíam limite de crédito disponível antes do aumento do limite.

Nos capítulos a seguir, temos a descrição da base de dados que será utilizada e a metodologia a ser seguida, muito próxima de Gross e Souleles (2001a). Ao final teremos os resultados encontrados e sua devida comparação com os demais resultados encontrados na literatura.

\section{Metodologia e Dados}

\subsection{Dados}

Para o trabalho proposto utilizaremos um painel de cartonistas de uma grande instituição financeira que possui $40 \%$ do mercado de cartões do Brasil. O painel foi construído partindo-se de 60 mil cartões ativos em maio/2013, sendo que definimos cartões como ativos quando estes apresentam alguma movimentação nos últimos 6 meses. Estes 60 mil cartões foram acompanhados pelo período de 23 meses, ou seja, até abril/2015. Neste período, alguns destes cartões se tornam inativos, ou por apresentarem atraso no pagamento, sendo então considerados enquadrados, ou porque o cartão não apresentou movimentação e assim foi suspenso, ou ainda porque o cliente solicitou o cancelamento do mesmo. No último mês do painel, apenas 70,46\% dos cartões continuam ativos. Como a intenção é acompanhar o comportamento de gastos, eliminamos as informações dos cartões a partir do momento em que estes se tornam inativos.

As variáveis do painel são referentes às informações da fatura do cartão. Um cartão pode não gerar fatura num determinado mês, ou porque a data para contabilização dos saldos a serem pagos ${ }^{3}$ ocorreu num feriado, ou no último final de semana do mês e assim o processo ocorre no dia útil seguinte, ou seja, no mês seguinte. Outra situação é quando não há valores para serem lançados na fatura. Assim, podemos ter cartões que não terão informações de fatura no painel em um mês específico. Podemos ter também cartões

3 Os valores lançados na fatura são contabilizados cerca de 10 dias antes da data de vencimento da fatura 
com duas informações de fatura num determinado mês, no caso de duas informações de fatura serem processadas num mesmo mês. Vale ressaltar que isto não altera a data de pagamento, que sempre fica num determinado dia do mês, a não ser que o cliente peça sua alteração.

Esta estrutura dos dados implica que o banco de dados resultado é um painel não balanceado. Como estamos considerando o cartão como unidade de observação ao longo do tempo, é possível que mais de um cartão de um mesmo indivíduo esteja na base.

As informações do painel são as emitidas na fatura do cartão, tais como saldo a ser pago, valor da taxa de juros caso não seja efetuado o pagamento, além de informações históricas relacionadas às faturas do cartão como valor do último pagamento efetuado. Há também informações cadastrais do cartão, como valor do limite de crédito disponibilizado, tempo de conta, indicador se o limite atual foi alterado pela instituição financeira ou por um pedido do cliente, linha de crédito ao qual o cartão pertence, e de crédito atribuído ao comportamento do cartão, além de informações sobre o cartonista como idade e região.

No período abrangido pelo painel, o valor médio do limite foi de $\mathrm{R} \$ 7$ mil reais, sendo de pouco mais de $\mathrm{R} \$ 6$ mil no primeiro mês de observação chegando a $\mathrm{R} \$ 8$ mil ao final do período. A taxa de juros média é de 11,41\% oscilando de $11 \%$ no primeiro mês para 11,8\% no último mês do painel. O saldo da fatura oscila de $\mathrm{R} \$ 960$ em maio/2013 para $\mathrm{R} \$ 1200$ em abril/2015, ficando numa média de $\mathrm{R} \$ 1$ mil se analisarmos todas as observações.

Não possuímos informações da renda do cartonista, mas há indícios que a linha de crédito ao qual o cartão pertence esteja relacionado a esta informação. Utilizamos a média da taxa de juros,o limite e o saldo observados em cada tipo de cartão para criarmos 4 categorias: as duas primeiras nomeadas como baixa e média baixa, com valores de taxa de juros acima da média e limite de crédito abaixo da média e as outras duas, média alta e alta, com valores taxa de juros abaixo da média e limite de crédito acima da média.

Temos que em 10\% das faturas, o limite de crédito disponível foi solicitado pelo cartonista, sendo que a proporção de solicitantes do limite disponível é maior nos últimos 
meses da base. ${ }^{4}$. O tempo de conta médio das faturas é de 65 meses, mais de 5 anos e isto nos sugere que cartões mais novos têm mais chances de se tornarem inativos que cartões mais antigos, uma vez que mantivemos apenas cartões ativos na amostra. A idade média do cartonista vai de 43 anos da primeira referência do painel para 45 anos. Nesta mesma linha, a distribuição das faturas pelas regiões do país se mantém constante ao longo das safras do painel, sendo que $64,7 \%$ das faturas pertencem a clientes da região Sudeste, seguidos por 14,5\% na região Nordeste, $10 \%$ na Sul, 6,3\% da Centro-Oeste e os demais na região Norte. Utilizando informações do IBGE e BCB, o painel aqui proposto é um pouco mais concentrado na região Sudeste comparando com a distribuição de pessoas bancarizadas no país. No demais, a ordenação das regiões segue a mesma. ${ }^{5}$

Com relação a efetuar o pagamento, pouco mais de $88 \%$ das faturas observadas efetuaram pelo menos o pagamento mínimo, $15 \%$ do saldo da fatura. ${ }^{6}$. Isto acaba se refletindo numa baixa probabilidade de default da carteira em análise. O índice de utilização do cartão a cada fatura, ou seja, percentual do limite efetivamente usado, foi de $25 \%$, em média, oscilando 3 pontos percentuais durante o período de observação. Nas categorias de cartões propostas, cartões baixa e média baixa possuem um índice de utilização acima da média e os média alta e alta o contrário, um índice de utilização abaixo da média.

Das faturas observadas no painel, pouco mais de $20 \%$ apresentam algum débito, ou seja, acumularam algum valor não pago entre dois fechamentos de fatura. O valor

4 O limite de crédito do cartão pode sofrer alterações ao longo do tempo, sendo esta ocasionada principalmente por: 1) Solicitação do cliente e 2) alteração automática, quando o emissor do cartão aumenta o limite de crédito disponível no cartão, como uma forma de incentivar o aumento do consumo do cartonista. Em ambos os casos, o emissor do cartão aprova o aumento do limite após analisar o comportamento de consumo e pagamento da fatura do cartão.

5 Schiavinatto e Schmidt (2011) indicam uma pesquisa onde 50\% no Norte, 47\% no Nordeste, $69 \%$ no Centro-Oeste, $67 \%$ no Sudeste e $70 \%$ da população do Sul possui conta em banco. Utilizando as informações da população do Censo de 2011 chegamos que o percentual de bancarizados no Brasil se divide nas regiões da seguinte forma: $6,2 \%$ no Norte, $22,2 \%$ no Nordeste, $46,6 \%$ no Sudeste, 17,2\% no Sul e $7,8 \%$ no Centro Oeste ((IBGE, ).

6 A legislação brasileira exige que um pagamento mínimo da fatura do cartão de crédito e $15 \%$ do saldo. Os cartonistas não têm opção de fazer um pagamento menor que este montante. Quando o pagamento não é feito, começa-se contar os dias de atraso e todos o saldo do cartão começa a ser corrigido pela taxa de juros, além de outros encargos financeiras e mora por não pagamento. Após um período de dias de atraso, a depender por instituição financeira, mesmo que o cartonista ainda tenha limite de crédito disponível, o cartão é bloqueado, ou seja, o limite restante não poderá ser usado a não ser que o saldo em atraso seja renegociado ou pago. 
médio não pago fica por volta de $\mathrm{R} \$ 750$. Estas faturas apresentam uma taxa de juros quase um ponto percentual maior que a média das observações, limite de crédito quase $\mathrm{R} \$ 3$ mil reais abaixo da média e com o saldo cerca de $\mathrm{R} \$ 200$ maior que o observado na média das faturas. O índice de utilização do cartão desta população chega a ser 20 pontos percentuais maior que a média da carteira, o que pode evidenciar um maior endividamento desta população que possui débitos em relação aos demais cartonistas que não possuem.

Os cartões que apresentam débitos se concentram nos tipos baixa e média baixa e nas regiões Norte/Nordeste em maior proporção que estas categorias representam na amostra. O público com débitos têm um maior percentual de cartões em que o limite de crédito disponível foi solicitado pelo cartonista. A idade e tempo de conta é um pouco menor que a média da carteira.

Estas comparações mostram que as faturas com débitos acumulados apresentam certas características diferentes em relação à amostra de faturas que compõem o painel e, logicamente, com as faturas que não acumularam saldos não pagos. Portanto, acrescentaremos o tempo de conta, idade, região, índice de utilização do cartão e tipo de cartão como variáveis explicativas ao modelo que vamos propor a seguir. Isto porque o efeito da variação dos débitos pode ser consequência de características do cartão ou do cartonista e precisamos isolar o efeito destas do efeito da alteração do limite ou da taxa de juros. Com a inclusão das variáveis listadas acima, os efeitos idiossincráticos de cada cartão ou cartonistas podem ser mensurados de forma que estes não afetem a estimação do efeito da variação do limite de crédito ou taxa de juros na variação dos débitos.

No painel, $2,7 \%$ das faturas observadas tiveram aumento do limite de crédito. O aumento do limite foi de cerca de $\mathrm{R} \$ 2$ mil reais e para aquelas faturas que tiveram aumento de limite, o percentual que possuem débitos é metade do observado no painel com todas as faturas.

Há 0,6\% das faturas que apresentam uma redução do limite, o que deve estar relacionado com o elevado endividamento destas: mais de $75 \%$ apresentavam débitos.

Aquelas faturas que sofreram aumento do limite de crédito são relacionadas a 
cartões mais novos e com índice de utilização do limite mais baixo que aquelas que não sofreram alteração de limite.

Já em relação a taxa de juros, 37\% das faturas observadas tiveram aumento da taxa de juros. Outras 34\% tiveram redução. O aumento da taxa de juros médio foi de $0,77 \%$ e a redução foi de $0,67 \%$.

Enquanto observamos diferenças em relação a proporção de contas com débitos, idade da conta e utilização entre as faturas que tiveram e não tiveram alteração do limite de crédito, não conseguimos ver as mesmas diferenças entre as faturas que tiveram aumento, redução ou mesmo não sofreram alteração na taxa de juros.

\subsection{Metodologia}

O objetivo deste trabalho é entender o quanto os débitos no cartão de crédito são afetados por uma mudança no limite de crédito ou na taxa de juros, ou seja, na quantidade de crédito ofertada ou no preço deste. Para isto, utilizaremos os dados do débito, $D_{i, t}$, variável dependente do modelo, que é o valor não pago entre duas faturas, também corrigido pelo taxa de juros e outros encargos como multa e mora. Utilizaremos também as informações do limite de crédito, $L_{i, t}$, e da taxa de juros, $i_{i, t}$, em cada período de tempo dos cartões de créditos da base de dados descrita acima. Utilizando a metodologia proposta por Gross e Souleles (2001a), mensuraremos o quanto uma alteração do limite de crédito afeta os débitos pela regressão de $\Delta D_{i, t}$ contra $\Delta L_{i, t}, \Delta L_{i, t-1}$ até $\Delta L_{i, t-s}$, onde $s$ é o horizonte de tempo a ser definido. O $\Delta D_{i, t}$ representa a alteração dos débitos entre $t$ e $t-1$, ou seja, $\Delta D_{i, t}=D_{i, t}-D_{i, t-1}$ enquanto $\Delta L_{i, t}$ representa a alteração do limite de crédito entre $t$ e $t-1$.

Como uma mesma conta de cartão de crédito pode sofrer várias alterações de limite e taxa de juros ao longo do tempo, estimar os efeitos utilizando um modelo com variáveis defasadas é mais aconselhável. Ao utilizarmos defasagens das variáveis explicativas, o modelo se torna mais adequado para lidar com os efeitos das mudanças nas variáveis ao longo da janela de tempo a ser utilizada, ou seja, para se torna mais adequado para 
capturar efeito acumulados ao longo do tempo da variável explicativa.

A primeira regressão que vamos explorar neste trabalho é:

$$
\Delta D_{i, t}=\beta_{0} \Delta L_{i, t}+\ldots+\beta_{s} \Delta L_{i, t-s}+\Omega^{\prime} X_{i, t}+\varepsilon_{i, t}
$$

Os coeficientes $\beta$ representam o efeito da variação do limite de crédito em cada período $s$ sobre os débitos contemporâneos. Então, $b_{s}=\sum_{j=0}^{s} \beta_{j}$ é o efeito acumulado das alterações de limite na janela $s$, ou seja, efeito de longo prazo da alteração dos débitos dados uma alteração do limite de crédito. Supondo que $s$ é um período de tempo suficiente para que $b_{s}$ tenha convergido para o efeito total de longo prazo, então $b_{s}$ representa o quanto da variação do limite do cliente é utilizado como forma de crédito. Em Gross e Souleles (2001a), $s$ foi definido igual a 12. O painel de dados proposto possui 23 meses de observações, com 1 mês perdido para obtermos as variações necessárias para a estimação. Então consideramos para os testes iniciais até 10 defasagens, ou seja, $s=10$, o que implica utilizarmos no máximo 10 meses de painel, com cerca de 450 mil observações, o que consideramos um bom tamanho de amostra para o trabalho.

As variáveis $X_{i, t}$ representam outras informações disponíveis na base de dados, descritas na subseção anterior, que utilizaremos para controlar demais fatores que afetem a variação dos débitos. Para tratar efeitos de sazonalidade, ciclos da economia e de gastos utilizaremos dummies dos meses $i$ dos dados. A idade da conta também é outra variável que utilizaremos para mensurar a relação entre o fluxo de gastos no cartão e alteração de limite, uma vez que contas mais nova possuem menores limites e menores gastos, o que gera menores variações de débitos. Já para o risco do cartonista, utilizaremos o escore de crédito, que mensura o risco dos valores gastos no cartão não ser pago.

Um efeito ressaltado por Gross e Souleles (2001a) é a endogeneidade na oferta de crédito. O problema aqui é quando o aumento ou diminuição da oferta de crédito é consequência de um movimento da demanda. No caso do cartão de crédito, estamos tentando mensurar o quanto o aumento do limite influencia os débitos e, caso o aumento do limite tenha sido solicitado pelo cliente, então não é o aumento do limite que estará 
causando os aumentos nos gastos, e consequentemente dos débitos. Para esta questão, utilizaremos uma variável disponível na base de dados que indica o motivo da alteração do limite de crédito, criando um indicador para quando a alteração do limite foi solicitada pelo cliente.

Além de uma solicitação direta do cliente, um consumo cada vez maior no cartão de crédito pode ter impulsionado o aumento do limite, e não o contrário como queremos mensurar. Para tratarmos este problema de simultaneidade, testaremos a estratégia proposta por Gross e Souleles (2001a) que é criar uma variável que indique à quantos meses foi a última alteração do limite de crédito do cartonista, utilizando esta como variável instrumental. Geralmente, o limite de crédito pode sofrer alteração automática apenas 6 meses após a última alteração. Assim, um cartão com demais variáveis iguais a outro mas com a última alteração de limite mais antiga tem maior probabilidade de um aumento de limite neste mês. Uma ideia que surgiu ao longo do trabalho foi utilizar um indicador de elegibilidade ao aumento de limite como instrumento para as alterações do limite de crédito. Este indicador foi criado a partir do escore de crédito, ferramenta utilizada na decisão de oferta de crédito, no caso, aumento do limite do cartão de crédito. Ele indica se o cartão pode receber um aumento de limite pois possui um risco de inadimplência dentro da banda que a instituição financeira deseja trabalhar e não implica que o cartão receberá o aumento de limite.

Outras variáveis de controle serão incluídas no modelo como idade, região, tipo de cartão e saldo da fatura.

Com a expansão da oferta de cartão no Brasil, é provável que quem é cartonista tenha mais de um cartão de crédito. Dado isto, incluiremos também como variável de controle os débitos e saldo dos demais cartões que o dono de um cartão da nossa amostra tenha. Com isto, podemos verificar o efeito que outros cartões de crédito podem ter sobre os débitos do cartão que estamos estudando.

A utilização das variáveis de controle acima nos permite verificar a robustez do efeito de longo prazo da variação do limite nos débitos, ou seja, a robustez do $b_{s}$. 
Ao aumentarmos o limite de crédito do cartão, aumentamos o montante de crédito disponível para consumo e assim, é possível um aumento nos débitos no cartão de crédito. Logo, esperamos que o efeito de longo prazo estimado seja positivo. Gross e Souleles (2001a) mensuraram um efeito de longo prazo positivo de $10 \%$ a $14 \%$ de variação dos débitos para uma variação do limite de crédito na janela de 12 meses. Para os autores, este resultado é uma evidência de que há restrição de crédito no mercado financeiro americano, colocando um questionamento sobre a teoria de renda permanente.

Se encontrarmos um resultado igual a Gross e Souleles (2001a), podemos concluir que assim como nos EUA, temos indício que há restrição de liquidez no mercado de crédito brasileiro.

Além do limite de crédito, o efeito das alterações nas taxas de juros sobre os débitos também serão analisados. Aplicaremos a mesma ideia da regressão anterior, entre limite de crédito e débitos, substituindo $\Delta L_{i, t}$ por $\Delta i_{i, t}$, em que é $\Delta i_{i, t}=i_{i, t}-i_{i, t-1}$. Assim, temos a segunda equação do trabalho:

$$
\Delta D_{i, t}=\alpha_{0} \Delta i_{i, t}+\ldots+\alpha_{h} \Delta i_{i, t-h}+\Psi^{\prime} Y_{i, t}+\varepsilon_{i, t}
$$

O efeito de longo prazo da alteração dos débitos dada uma alteração da taxa de juros será obtido pela soma dos $\alpha$ estimados pela equação acima, ou seja, $a_{h}=\sum_{j=0}^{h} \alpha_{j}$.

A base de dados utilizada para esta análise é a mesma de antes, de forma que teremos $h=10$, no máximo. As variáveis $Y_{i, t}$ representam os demais fatores que afetam os débitos e devemos incluir na estimação para obtermos um resultado mais robusto. Dentre estas variáveis estão escore de crédito, idade da conta, dummies dos meses utilizados na estimação e as demais variáveis que utilizamos para obter o efeito da relação débitos e limite de crédito.

Diferente do limite de crédito, as alterações da taxa de juros não são solicitadas pelo cartonista, porém o comportamento de compras e débitos acumulados no cartão pode afetar a taxa de juros aplicada a este de forma que também temos um problema de simultaneidade na relação débitos e taxa de juros. Para lidar com este problema 
trabalharemos com variáveis instrumentais na estimação da relação de taxa de juros e débitos.

Esperamos que o efeito de longo prazo estimado seja negativo, ou seja, um aumento da taxa de juros reduza os débitos no cartão de crédito. Um aumento da taxa de juros do

cartão de crédito aumenta o valor do montante não pago da fatura, ou seja, os débitos. É como se o crédito que o cartão disponibiliza para o cartonista ficasse mais caro. Supondo que a utilidade do consumo presente em relação ao consumo futuro se mantenha a mesma, o aumento da taxa de juros torna este adiantamento de consumo mais caro podendo superar a utilidade que este trará. Por este motivo esperamos a redução dos débitos. Em Gross e Souleles (2001a), o efeito de longo prazo dos débitos à alteração da taxa de juros foi de -110 dolares para cada 1 ponto percentual de aumento da taxa de juros num horizonte de 9 meses.

Os efeitos de longo prazo dos débitos em relação a alteração no limite de crédito e taxa de juros podem ser diferentes dependendo algumas características do cartão e do cartonista. Por exemplo, Gross e Souleles (2001a) estimam um efeito de longo prazo do limite de crédito bem maior para os cartões com elevada taxa de utilização do limite que para os demais cartões. Para a análise de heterogeneidade proposta neste trabalho, pretendemos estimar o efeito de longo prazo dos débitos em relação a alteração do limite de crédito e taxa de juros por faixas de índice de utilização do limite de crédito, escore de crédito e tipo de cartão. Em cada análise, na seção 5.3, iremos explicar como definimos as categorias de cada uma das três variáveis da análise proposta e o que esperamos estimar em cada situação.

\section{Resultados}

\subsection{Efeito da variação do limite de crédito}

O primeiro passo para verificarmos o efeito da alteração do limite na variação dos débitos foi testar quantas defasagens da variação do limite deveríamos utilizar para 
identificarmos o efeito de longo prazo em questão. ${ }^{7}$ Este efeito implica que para cada $\mathrm{R} \$ 1$ de aumento de limite, o valor estimado é o montante que se transforma em débitos em um horizonte de meses que iremos definir.

A primeira regressão teve como variáveis independentes a variação do limite de crédito do mesmo período da variação dos débitos e dummies que identificam os meses presentes na amostra. Na regressão seguinte, mantivemos as mesmas variáveis da primeira regressão e foi incluída a variação de limite de crédito do período imediatamente anterior ao da variável resposta. Assim se seguiram as regressões posteriores, incluindo uma a uma as defasagens da variação do limite de crédito até termos incluído todas as 10 defasagens propostas inicialmente.

Para cada regressão, o efeito de longo prazo foi obtido como a soma dos betas relacionados a cada variação do limite de crédito presente na equação. Na figura seguinte, cada ponto do gráfico representa o efeito de longo prazo de um modelo com o número de defasagens da variação do limite de crédito apresentado no eixo da abcissa.

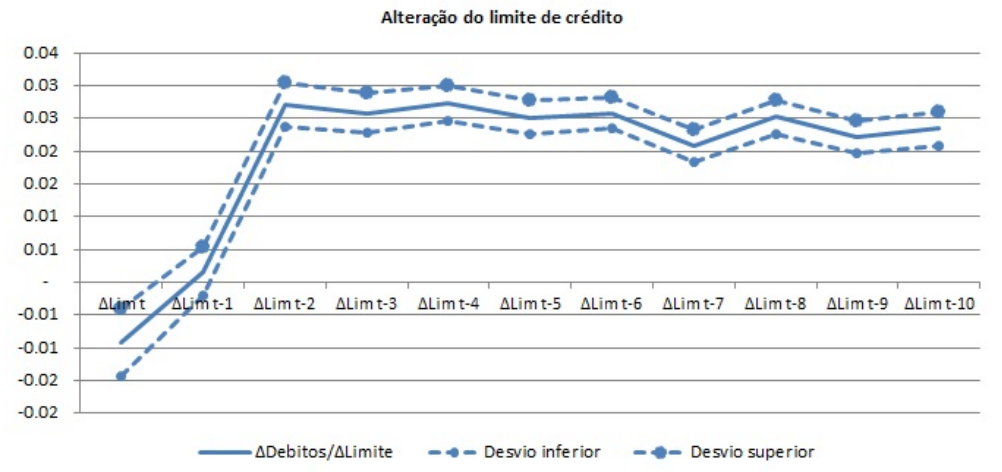

Figura 1 - Efeito de longo prazo dos débitos em relação à variação do limite de crédito conforme incluímos defasagens da variação do limite de crédito. Fonte: Elaborado pelo autor.

Pelo gráfico anterior, observamos que o efeito de longo prazo tende à ser alcançado na estimação com dois meses de defasagens da variação do limite de crédito enquanto a inclusão de variações do limite de crédito adicionais, como a partir do sétimo mês, tem efeito que podemos considerar nulo.

$\overline{7}$ Relembrando, o efeito de longo prazo, $b_{s}$, é estimado pela soma dos $\beta$ da equação 1 descrita na seção de metodologia. 
Na amostra que utilizamos para a construção do resultado anterior, há cartões que o limite de crédito foi alterado por solicitação do cartonista ${ }^{8}$. Nestes casos, a aumento de limite de crédito é consequência de um efeito de demanda por mais crédito. Sendo assim, é mais provável que o desejo de se aumentar os débitos seja causa do aumento do limite e não o contrário, que é o que queremos mensurar. Então, devemos estimar separadamente o efeito de longo prazo entre aqueles que solicitaram aumento do limite de crédito do cartão e aqueles que a alteração do limite de crédito foi automática.

Para cada subpopulação, estimamos o efeito de longo prazo utilizando duas defasagens da variação do limite Os resultados se encontram na Tabela 1, equações 3 e 4. Para aqueles que solicitaram e obtiveram alteração do limite, o efeito de longo prazo estimado foi 0.1003 , estatisticamente diferente de zero à $5 \%$ de nível de significância. Já para aqueles que tiveram o aumento do limite automático, o efeito de longo prazo foi 0.0012 , sendo este não estatisticamente diferente de zero, mesmo à 10\% de nível de significância.

Nos gráficos a seguir, mensuramos o efeito de longo prazo incluíndo uma a uma as defasagens da variação do limite na estimação e observamos como os efeitos de longo prazo são distintos entre as duas subpopulações.

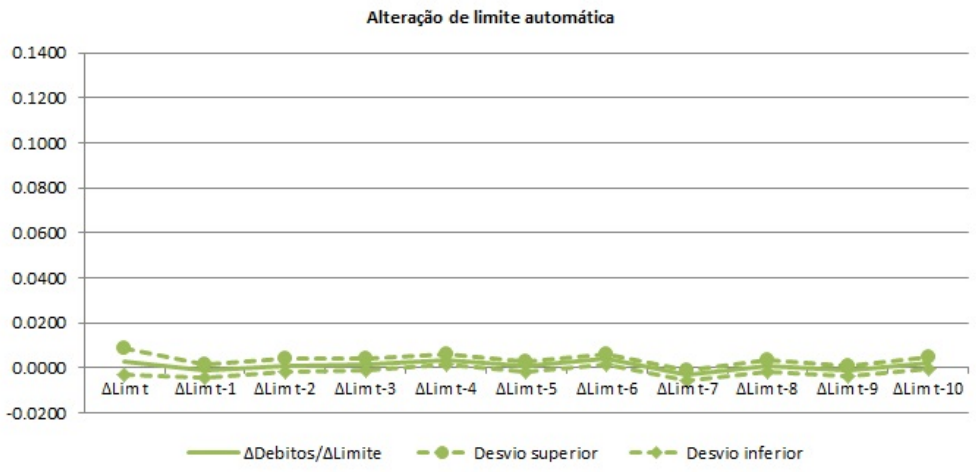

Figura 2 - Efeito de longo prazo dos débitos em relação a variação do limite - Alteração automática do limite de crédito. Fonte: Elaborado pelo autor.

Nota-se que a evolução do efeito de longo prazo, conforme utilizamos mais defasagens da variação do limite na estimação, é diferente entre quem solicitou a alteração do limite de crédito e quem teve alteração automática. Para a população que teve alteração automática

8 Lembrando que na amostra deste trabalho há cartões que o limite de crédito é alterado por solicitação do cartonista e outros que o limite de crédito é alterado de forma automática, como uma forma de incentivar o aumento do consumo do cartonista. 


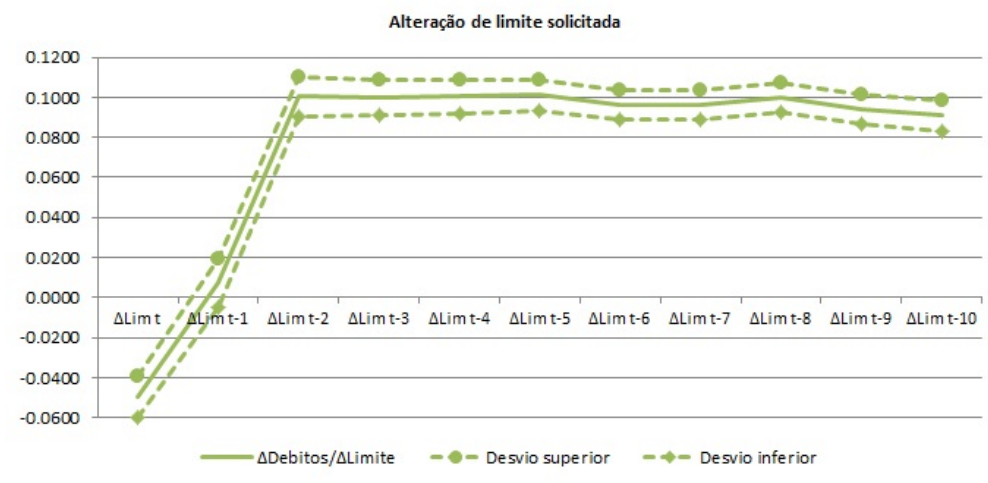

Figura 3 - Efeito de longo prazo dos débitos em relação a variação do limite - Alteração do limite de crédito solicitada pelo cartonista. Fonte: Elaborado pelo autor.

do limite de crédito, o efeito de longo prazo sofre alteração até a inclusão da décima defasagem da variação do limite, principalmente em relação ao sinal do efeito, negativo ou positivo. Este resultado é diferente do observado para aqueles em que a alteração de limite foi solicitada, aonde o efeito varia fortemente até a inclusão da segunda defasagem e depois se mantem constante.

A magnitude do efeito de longo prazo também é diferente. O efeito de longo prazo para aqueles que tiveram alteração automática de limite ficou em torno de zero, porém estatisticamente insignificante, de forma que ainda não podemos concluir que alterações do limite de crédito não afetam os débitos do cartão. Já o efeito de longo prazo estimado para aqueles que solicitaram à alteração de limite é muito mais elevado e estatisticamente significante, conforme esperado, uma vez que supomos que a solicitação do aumento de limite foi para propiciar um aumento dos gastos, o que pode causar um aumento dos débitos.

O efeito de longo prazo que queremos mensurar é o obtido na população que teve alteração automática de limite do cartão de crédito, pois são nestes cartões que a variação dos débitos é consequência da variação do limite de crédito. Sendo assim, as estimações que serão apresentadas a seguir foram realizadas apenas na parte da amostra onde a alteração do limite foi automática.

Suspeitamos que os resultados anteriores, tanto para a população que solicitou a alteração de limite, quanto para aqueles que tiveram alteração automática, foram afetados 
por variáveis omitidas ${ }^{9}$. Neste sentido, iremos explorar uma opção para controlar o efeito destas variáveis omitidas no resultado: a introdução de efeitos fixos por cartonista. A equação 7 da tabela a seguir contém a estimação com 10 defasagens da variação do limite mais dummies de meses utilizando efeitos fixos por cartonista. O resultado é um efeito de longo prazo negativo porém não muito diferente do que encontramos nas estimações anteriores. Concluímos então que os resultados encontrados anteriormente não são consequência da forma utilizada para estimação. Sendo assim, optou-se por continuar a mensuração do efeito de longo prazo utilização a forma funcional de equações em diferenças proposta na seção de metodologia.

Uma vez que os efeitos fixos não foram muito eficazes no controle dos efeitos que variáveis omitidas podem ter sobre os débitos, iremos colocar controles adicionais relacionados ao cartão de crédito e do cartonista no modelo, ainda mantendo 10 defasagens para o cálculo dos efeitos de longo prazo do limite sobre os débitos. Como características dos cartonistas, temos as informações de idade e região onde este mora. Além destas, utilizaremos uma informação qualitativa, 'tipo de cartão' ${ }^{10}$ que tende a agrupar cartonistas com perfis próximos no que diz respeito ao padrão de vida e acesso à crédito.

Das informações do cartão, temos o tempo de conta, sendo que contas mais antigas têm maior probabilidade de terem sofrido mais alterações de limite ao longo do tempo e ter um limite maior, caso possuam um bom comportamento pagador. Outra informação que utilizaremos é escore de crédito do cartão que resumi muitas informações do comportamento de compras e pagamento do cartão. E por fim, utilizaremos o saldo, ou seja, o valor total gasto no cartão. Aqui vale ressaltar que o saldo é o valor que será cobrado do cliente na fatura. Agrega tanto as compras apuradas no período quanto valores não pagos nos meses anteriores e o juros respectivos à estes não pagamento. Como dito anteriormente, o débito do cartão, variável dependente do modelo, é o valor não pago entre duas faturas, também corrigido pelo taxa de juros e outros encargos como multa e mora.

9 Numa estimação aonde temos problema com variável omitida, os parâmetros estimados são considerados viesados, uma vez que o termo de erro da equação não é mais considerado exógeno

10 Utilizamos a média da taxa de juros, limite e saldo observados em cada tipo de cartão para criarmos 4 categorias: as duas primeiras nomeadas como baixa e média baixa, com valores de taxa de juros está acima da média e limite de crédito abaixo da média e as outras duas, média alta e alta, com valores taxa de juros abaixo da média e limite de crédito acima da média. 
Todas as variáveis listadas acima foram utilizadas na estimação de Gross e Souleles (2001a). As variáveis explicativas acima foram defasadas um mês em relação ao mês de referência dos débitos, sendo que as variáveis numéricas, ou seja, escore, idade da conta, saldo e idade foram utilizadas como um polinômio cúbico, para permitirmos uma relação possivelmente não linear destas variáveis com a variável dependente. Iremos apresentar os modelos com estas variáveis sendo introduzidas sequencialmente, de forma a deixar mais claro o papel que cada controle tem em limitar o efeito de variáveis omitidas.

O escore de crédito foi a primeira variável a ser incluída na regressão. Isto porque é de se esperar que esta variável possuia muitas informações do cartão que podem ser fortemente relacionadas à variação dos débitos. O efeito de longo prazo estimado para a população com alteração automática do limite de crédito foi de 0,0060, muito próximo ao estimado anteriormente, porém não mais insignificante estatisticamente. Com a inclusão do saldo e da idade da conta, o efeito de longo prazo foi 0,0336 , bem maior que o estimado na versão anterior do modelo e estatiscamente significante, mais uma vez.

Por fim, com a inclusão da informação do tipo de cartão, idade do cartonista e região o efeito de longo prazo estimado foi 0,0339 .

O aumento do valor do efeito de longo prazo e a mudança na significância do parâmetro com a inclusão da idade da conta e do saldo serve como indício de que nas estimações anteriores, parte do efeito da variação do limite sobre os débitos estava sendo influenciada por informações omitidas que se refletiam nos parâmetros estimados.

Dos resultados obtidos até este momento, é possível concluir que o efeito da variação 


\begin{tabular}{|c|c|c|c|c|}
\hline & & Ef. Longo Prazo & Erro Padrão & \# Obs \\
\hline 1) & $\Delta L_{i, t-2}+$ Dummies de meses & $0.0271(*)$ & 0.0029 & 874059 \\
\hline 2) & $\Delta L_{i, t-10}+$ Dummies de meses & $0.0234(*)$ & 0.0044 & 492567 \\
\hline 3) & $\Delta L_{i, t-2}$ automática + Dummies de meses & 0.0012 & 0.00251 & 781133 \\
\hline 4) & $\Delta L_{i, t-2}$ solicitada pelo cliente + Dummies de meses & $0.1003(*)$ & 0.008585 & 92926 \\
\hline 5) & $\Delta L_{i, t-10}$ automática + Dummies de meses & 0.0024 & 0.004099 & 436820 \\
\hline 6$)$ & $\Delta L_{i, t-10}$ solicitada pelo cliente + Dummies de meses & $0.0908(*)$ & 0.012653 & 55747 \\
\hline 7) & $\begin{array}{l}\Delta L_{i, t-10} \text { automática }+ \text { Dummies de meses - } \\
\text { Estimação por efeitos fíxos }\end{array}$ & $-0.0066(*)$ & 0.003212 & 426820 \\
\hline 8) & $\Delta L_{i, t-10}$ automática + Dummies de meses + escore & $0.0060(*)$ & 0.001261 & 436820 \\
\hline 9) & $\begin{array}{l}\Delta L_{i, t-10} \text { automática }+ \text { Dummies de meses }+ \text { escore } \\
+ \text { saldo }+ \text { idade da conta }\end{array}$ & $0.0336(*)$ & 0.001549 & 427281 \\
\hline 10) & $\begin{array}{l}\Delta L_{i, t-10} \text { aut. }+ \text { Dummies de meses }+ \text { escore }+ \text { saldo } \\
+ \text { idade da conta }+ \text { tipo do cartão }+ \text { idade e região }\end{array}$ & $0.0339(*)$ & 0.001552 & 427281 \\
\hline
\end{tabular}

Tabela 1 - Efeito de longo prazo dos débitos em relação a variação do limite - Diferentes especificações de estimação. (*) indica efeito de longo prazo signifincante à $5 \%$. Fonte: Elaborado pelo autor.

dos débitos dado a variação do limite de crédito não é direcionado por uma relação inversa, ou seja, pelo desejo de se aumentar os débitos ocasionando o aumento do limite, uma vez que separamos o efeito estimado entre alterações de limite solicitadas e alterações automáticas. Mesmo sendo estimado um valor baixo, este é estatisticamente significante o que nos leva a afirma que relação entre débitos e limite é positiva, ou seja, uma variação positiva do limite de crédito pode levar à um aumento dos débitos.

O baixo valor encontrado nesta análise em relação ao efeito de longo prazo de $10 \%$ à $14 \%$ exposto por Gross e Souleles (2001a) pode ser consequência de ainda não se ter conseguido eliminar completamente os efeitos da endogeneidade sobre os parâmetros estimados. O aumento dos gastos, que pode levar ao aumento dos débitos, é uma das características observadas pelo sistema financeiro para se decidir pelo aumento do limite de crédito. Desta forma, podemos ter um problema de simultaneidade: o aumento dos gastos, levaria ao aumento do limite de crédito, que pode levar à gastos adicionais. Neste caso, os resultados encontrados anteriores sofrem de viês na estimação, uma vez que o termo de erro da equação não tende a zero com o aumento da amostra. Podemos obter estimativas consistentes na presença de simultaneidade utilizando variáveis instrumentais. Estas variáveis precisam atendar duas propriedades. A primeira delas é que sejam correlacionadas com a variável independente que se suspeita endógena (força dos instrumentos); a segunda 
propriedade é que ela não afete a variável independente diretamente (restrição de exclusão).

Em Gross e Souleles (2001a), utilizou-se número de meses desde a última alteração de limite como instrumento para a variação do limite de crédito. Para os dados aqui utilizados, a alteração do limite de crédito ocorre com um intervalo mínimo de 6 meses. Assim, quanto mais tempo tenha passado desde a última alteração de limite de crédito, maior a probabilidade de que este sofra uma alteração no mês corrente.

Utilizando os meses desde última alteração do limite de crédito como variável instrumental para cada variação do limite utilizada na equação, estimamos um efeito de longo prazo igual 0,1198, três vezes maior que o valor estimado anteriormente e bem próximo à 0,111 , que foi o valor encontrada por Gross e Souleles (2001a). Este resultado é um indicativo de que as estimações anteriores, realizadas sem o uso de variáveis instrumentais, são viesadas devido ao problema de simultaneidade apresentado anteriormente. Do ponto de vista de importância prática, este resultado nos leva a concluir que a variação do limite de crédito tem um efeito positivo e significante sobre a variação dos débitos.

Na equação 12, junto com os instrumentos de meses desde a última alteração do limite utilizamos um indicador de elegibilidade de aumento de limite. Este indicador é baseado no escore de crédito e indica se o cartão é elegível a um aumento de limite de crédito ou não. Com a inclusão deste novo instrumento estimamos um efeito de longo prazo de 0.1144 , muito próximo ao valor estimado anterior.

Em relação à validade dos instrumentos propostos, o teste $\mathrm{F}$ das regressões de cada endógena contra os instrumentos e exógenas foi sempre maior que 20, valor limiar que podemos utilizar para afirmar que os instrumentossão correlacionados com a variável endógena em questão. Realizamos também o teste de Hansen, dos resíduos em relação aos instrumentos e demais exógenas. O valor baixo que obtemos da estatística $R^{2 *} \mathrm{~N}$ é outro indicativo que estamos tratando o problema de simultaneidade com bons instrumentos. Os resultados dos testes estão nas tabelas 3 e 4 abaixo.

Os resultados anteriores, utilizando variáveis instrumentais, aonde encontramos um efeito de longo prazo do limite de crédito sob os débitos do cartão, nos permitem 
concluir que os valores baixos encontrados anteriormente são resultado de não se ter conseguido lidar completamente com os efeitos da endogeneidade. O efeito de longo prazo estimado, 0,11, indica que para cada $\mathrm{R} \$ 100$ reais de aumento dos débitos do cartão, aproximadamente $\mathrm{R} \$ 11$ se tornaram débitos, no horizonte de 10 meses. Isto significa que $10 \%$ do aumento do limite é utilizado como crédito, impulsionando o consumo além da renda corrente do cartonista. Este resultado positivo e significante é uma evidência de que há restrição de crédito do mercado financeiro brasileiro assim como o resultado de $10 \%$ à 14\% encontrado por Gross e Souleles (2001a) foi uma evidência de restrição de crédito para o mercado americano.

Após explorarmos a melhor forma de mensurar o efeito de longo prazo dos débitos em relação ao limite de crédito, seguiremos com outra análise. Vamos verificar se o efeito de longo prazo muda quando incluímos informações de outros cartões que os cartonistas de nossa amostra tenha. Partindo da equação 12, incluímos um indicador se o cartonista possui outro cartão de crédito como variável independente. O efeito de longo prazo estimado foi 0,1137, conforme mostrado na estimação 13. Na equação 14, além do indicador de possuir outro cartão, incluímos o valor dos débitos nestes demais cartões e novamente, o valor estimado de longo prazo foi 0,1115 . Ambos os valores estimados foram estatisticamente significantes, à $5 \%$ de significância

Ao incluirmos informações de outra forma de acesso a crédito, no caso, outro cartão de crédito, buscamos identificar a interdependência entre estas formas de crédito. Como o efeito de longo prazo estimado com a inclusão das informações de outros cartões, 0,1115, não foi muito diferente da estimação anterior, 0,1143, concluímos que não há dependência entre estas formas de crédito, de modo que alterações em um cartão não impactam o comportamento do cartonistista nos demais cartões que este tenha. Este resultado se aproxima do encontrado em Ponce, Seira e Zamarripa (2014), no qual grande parte dos cartonistas não migra seus gastos quando há alterações na taxa de juros de um dos cartões.

Ainda sobre esta análise entre fontes de crédito, precisamos ressaltar que o percentual de cartonistas com outro cartão foi pequeno perto dos dados financeiros. São grandes a chances de mais cartonistas da amostra terem mais de um cartão, porém os 
demais cartões podem não ser da mesma instituição financeira da qual obtivemos os dados utilizados neste trabalho. Outro fator a ressaltar é que não apenas o cartão de crédito funciona como fonte de crédito no mercado financeiro. Uma amostra com informações de outras fontes de financiamento, como crédito pessoal, cheque especial, poderiam tornar a conclusão da análise anterior mais rica e definitiva.

\begin{tabular}{|c|c|c|c|c|}
\hline & & Ef. Longo Prazo & Erro Padrão & \# Obs \\
\hline 11) & $\begin{array}{l}\Delta L_{i, t-10} \text { aut. }+ \text { Dummies meses }+ \text { escore }+ \text { saldo } \\
\text { idade da conta }+ \text { tipo do cartão }+ \text { idade e região } \\
+ \text { IV: Meses desde a última alterção de limite }\end{array}$ & $0.1198\left(^{*}\right)$ & 0.010488 & 426089 \\
\hline 12) & $\begin{array}{l}\Delta L_{i, t-10} \text { aut. }+ \text { Dummies meses + escore + saldo } \\
\text { idade da conta + tipo cartão + idade e região + IV: } \\
\text { Meses desde última alt. limite + Ind. Elegibilidade }\end{array}$ & $0.1144(*)$ & 0.003168 & 426089 \\
\hline 13) & 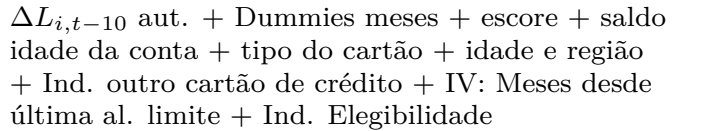 & $0.1137(*)$ & 0.003152 & 426089 \\
\hline 14) & $\begin{array}{l}\Delta L_{i, t-10} \text { aut. }+ \text { Dummies de meses }+ \text { escore }+ \text { saldo } \\
+ \text { idade da conta }+ \text { tipo do cartão }+ \text { idade e região } \\
+ \text { Ind. outro cartão de crédito }+ \text { Débitos outro cartão } \\
+ \text { IV: Meses desde últ. alteração limite } \\
+ \text { Ind. Elegibilidade }\end{array}$ & $0.1115(*)$ & 0.003152 & 426089 \\
\hline
\end{tabular}

Tabela 2 - Efeito de longo prazo dos débitos em relação a variação do limite - Diferentes especificações de estimação - Demais análises. (*) indica efeito de longo prazo signifincante à 5\%. Fonte: Elaborado pelo autor.

\begin{tabular}{cc}
\hline \multicolumn{2}{c}{ Teste $\mathbf{F}$} \\
\hline \multicolumn{2}{c}{ H0: Parâmetros dos instrumentos } \\
serem conjuntamente iguais a 0 \\
\hline Endógena & F Value \\
\hline \multicolumn{1}{c}{$\Delta$ Lim $_{t}$} & 5831.62 \\
$\Delta$ Lim $_{t-1}$ & 6208.55 \\
$\Delta$ Lim $_{t-2}$ & 6387.01 \\
$\Delta$ Lim $_{t-3}$ & 6399.38 \\
$\Delta$ Lim $_{t-4}$ & 6388.9 \\
$\Delta$ Lim $_{t-5}$ & 6653.47 \\
$\Delta$ Lim $_{t-6}$ & 6970.42 \\
$\Delta$ Lim $_{t-7}$ & 7032.64 \\
$\Delta$ Lim $_{t-8}$ & 7487.08 \\
$\Delta$ Lim $_{t-9}$ & 7508.98 \\
$\Delta$ Lim $_{t-10}$ & 517.56 \\
\hline
\end{tabular}

Tabela 3 - Teste F para os instrumentos. Fonte: Elaborado pelo autor.

\begin{tabular}{|c|c|}
\hline \multicolumn{2}{|c|}{ Teste Hansen } \\
\hline $\begin{array}{l}\text { Regressão dos } \\
\text { equação } 13 \mathrm{em} \\
\text { exôgenas e ins }\end{array}$ & $\begin{array}{l}\text { luos da } \\
\text { ação as } \\
\text { nentos }\end{array}$ \\
\hline $\begin{array}{rr}\text { R2 } & \\
\text { No Variáveis }\end{array}$ & $\begin{array}{r}0.0157 \\
44\end{array}$ \\
\hline
\end{tabular}

Tabela 4 - Teste de Hansen. Fonte: Elaborado pelo autor. 
Os resultados desta seção nos permitem concluir que alterações no limite de crédito ocasiona aumento dos débitos numa magnitude bem próxima ao encontrado no trabalho de Gross e Souleles (2001a). Mesmo o mercado brasileiro tendo características diferentes do americano, de onde foram extraídos os dados de Gross e Souleles (2001a), em 10 meses, 11\% do limite de crédito tornam-se débitos enquanto de 10\% a 14\% do limite de crédito se torna débitos nos EUA. Ao lidarmos com o problema de simultaneidade, propusemos o indicador de elegibilidade como uma variável instrumental juntamente com o número de meses desde última alteração do limite, que é proposta em Gross e Souleles (2001a).

Ao incluirmos informações dos demais cartões que os indivíduos da nossa amostra tenha, não encontramos um indicativo de dependência entre cartões de um mesmo indivíduo, pois o efeito de longo prazo estimado na equação que consideramos mais adequada não sofreu alteração em relação ao estimado com informações de saldo e débitos de outros cartões.

Podemos considerar o efeito de longo prazo estimado positivo e significante como uma evidência de que há restrição de crédito do mercado financeiro brasileiro.

Na seção seguinte analisaremos o efeito de longo prazo dos débitos dado uma alteração na taxa de juros e na seção posterior iremos verificar se o efeito de longo prazo encontrado para alterações de limite e taxa de juros são diferentes de acordo com algumas caracteristicas do cartão como escore de crédito e índice de utilização do limite.

\subsection{Efeito da variação da taxa de juros}

Da mesma forma que a subseção anterior, primeiramente precisamos encontrar quantas defasagens da taxa de juros precisaremos incluir na equação para obtermos o efeito de longo prazo da taxa de juros sob os débitos. Neste caso, o efeito de longo prazo significa que a cada aumento de 1 p.p. da taxa de juros, os débitos se alteram na magnitude do valor estimado.

Os efeitos de longo prazo estimados conforme vamos incluído defasagens da taxa de juros estão expostos no gráfico abaixo. O número de defasagens da variação da taxa de 
juros é apresentado no eixo da abcissa.

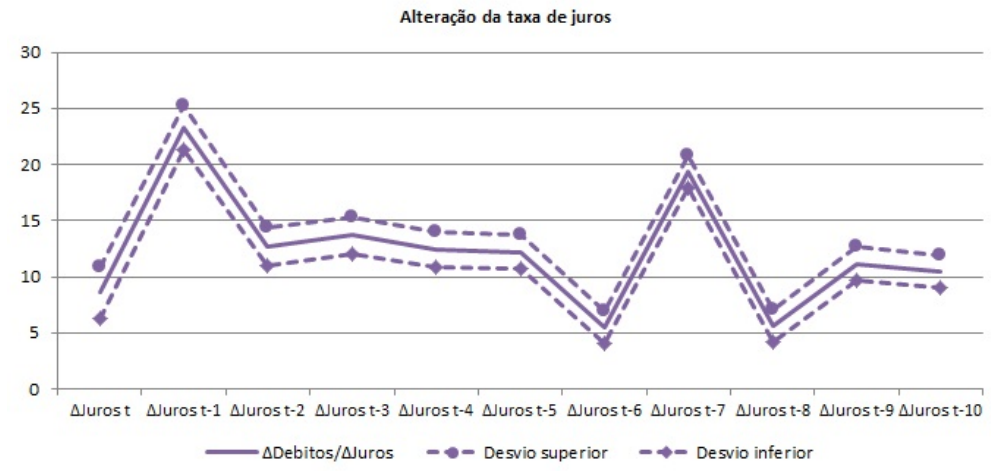

Figura 4 - Efeito de longo prazo dos débitos em relação à variação da taxa de juros conforme incluímos defasagens da variação do limite de crédito. Fonte: Elaborado pelo autor.

Todos os efeitos de longo prazo estimados foram positivos. Se nos basearmos em Gross e Souleles (2001a) em que o efeito de longo prazo dos débitos em relação à uma alteração da taxa de juros foi estimado como uma redução de 110 doláres para um aumento de 1 ponto percentual na taxa de juros, esperaríamos estimar valores negativos e significantes estatisticamente.

Uma possível explicação é que o resultado acima esteja sendo afetado pelos cartonistas que pararam de honrar seus pagamentos da fatura do cartão de crédito e, consequentemente, têm seus débitos corrigidos pela taxa de juros do crédito. Para estimarmos o efeito de longo prazo da taxa de juros nos débitos, precisamos de cartões para os quais seja registrado algum pagamento da fatura, para verificarmos se alterações na taxa de juros mudam o comportamento de pagamento, no caso, o montante do saldo da fatura que o cartonista decidirá utilizar como forma de crédito.

Utilizamos uma variável da base de dados que indica se o cartonista fez pelo menos o pagamento mínimo da fatura, 15\%, para separarmos a amostra de cartões em duas subamostras: aqueles que efetuaram pelo menos o pagamento mínimo e aqueles que não efetuaram nenhum pagamento. Para cada subamostra, estimamos o efeito de longo prazo incluindo, uma a uma, as variações da taxa de juros contemporânea e defasadas e os resultados estão nas figuras 5 e 6 abaixo. 


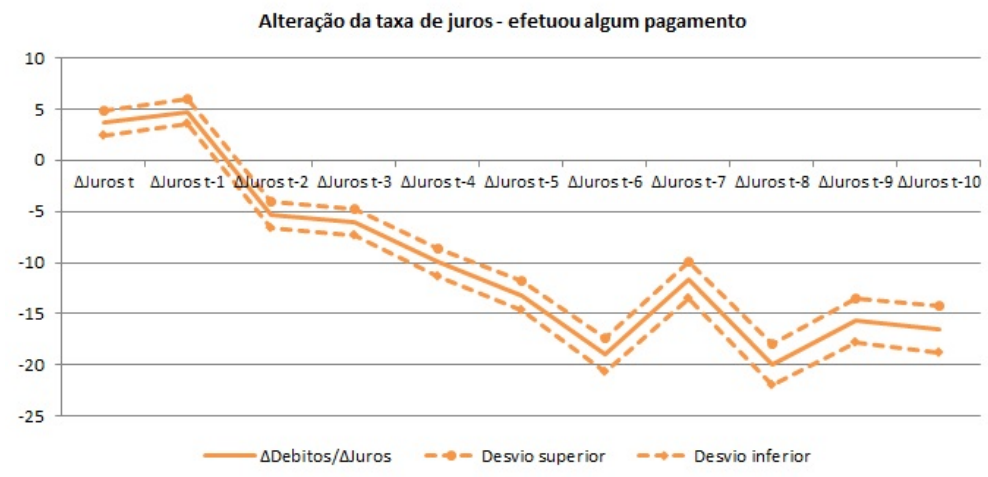

Figura 5 - Efeito de longo prazo dos débitos em relação à variação da taxa de juros Cartão com pagamento. Fonte: Elaborado pelo autor.

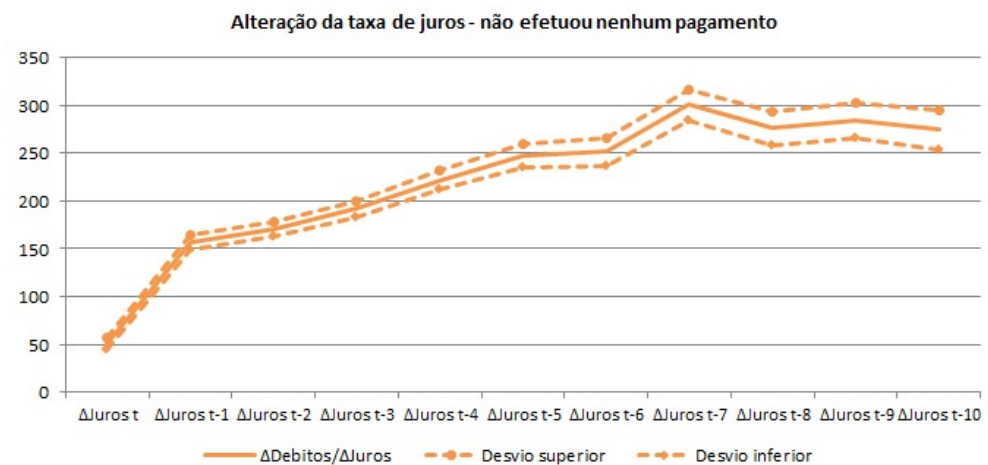

Figura 6 - Efeito de longo prazo dos débitos em relação à variação da taxa de juros Cartão sem pagamento. Fonte: Elaborado pelo autor.

Os efeitos de longo prazo estimados em cada subpopulação são bastante diferentes. Para os que não fizeram nem o pagamento mínimo, o efeito de longo prazo é positivo e crescente, conforme esperávamos, dado que os débitos não estão sendo pagos e estão sendo corrigidos pela taxa de juros. Já para aqueles cartões que tiveram pelo menos o pagamento mínimo feito, o efeito de longo prazo estimado foi negativo, consistente com o estimado em Gross e Souleles (2001a).

Olhando para a população que fez pelo menos o pagamento mínimo, o efeito de longo prazo oscila bastante após a inclusão da sexta defasagem da variação da taxa de juros, porém até a inclusão da décima defasagem o efeito de longo prazo estimado é estatisticamente significante. Sendo assim, além de utilizarmos apenas o público com pelo menos o pagamento mínimo feito, utilizaremos dez defasagens da taxa de juros para as equações a seguir. 
Seguiu-se uma estrutura de análise muito similar àquela apresentada para o caso das alterações de limites. Primeiro, testou-se a forma utilizada para a estimação do efeito de longo prazo. O valor estimado na equação 4, utilizando efeitos fixos, foi negativo e menor que o estimado na equação em diferenças. Optamos por utilizar a forma funcional da equação 2, que é a proposta na seção de Metodologia, para seguir com a estimação.

Como dito na seção anterior, outras variáveis podem explicar a alteração dos débitos, de forma que mesmo que o resultado de longo prazo estimado até o momento tenha o sentido esperado, este pode carregar problema de viés de variáveis omitidas na equação. Incluiremos a mesma lista de variáveis explicativas que utilizamos na estimação variação do limite versus variação dos débitos, sendo estas variáveis: escore de crédito do cartão, idade, região, saldo e tipo do cartão. Novamente, as variáveis numéricas, ou seja, escore, idade da conta, saldo e idade foram utilizadas como um polinômio cúbico.

A tabela 5 contêm os valores estimados do efeito de longo prazo com diferentes controles e especificações. Ao incluirmos o escore como variável explicativa, o efeito de longo prazo estimado reduziu a magnitude, de $-16,52$ para $-7,03$. Com a inclusão do saldo e do tempo de conta na equação, o valor estimado foi muito próximo do anterior, -7,39. Ao incluirmos o tipo do cartão, idade e região como explicativas, o efeito de longo prazo estimado foi positivo, 3,15. Neste caso, optamos por retirar a variável de tipo de cartão da estimação, e obtemos um efeito estimado próximo à -7 .

Estimarmos um efeito de longo prazo dos débitos em relação a uma alteração da taxa de juros próximo de -7 significa disser que para cada aumento de 1 ponto percentual da taxa de juros, em 10 meses, os débitos irão reduzir em $\mathrm{R} \$ 7$. Este valor é muito menor que o estimado em Gross e Souleles (2001a), onde para cada 1 ponto percentual de aumento da taxa de juros, a redução dos débitos é de U\$ 110 em 9 meses. 


\begin{tabular}{|c|c|c|c|c|}
\hline & & Ef. Longo Prazo & Erro Padrão & \# Obs \\
\hline 1) & $\Delta i_{i, t-10}+$ Dummies de meses & $10.43(*)$ & 0.7266 & \\
\hline 2) & $\Delta i_{i, t-10}$ cartões com pagamento + Dummies meses & $-16.52(*)$ & 1.1469 & \\
\hline 3) & $\Delta i_{i, t-10}$ cartões sem pagamento + Dummies meses & $274.53(*)$ & 10.029 & \\
\hline 4) & $\begin{array}{l}\Delta i_{i, t-10} \text { cartões com pagamento }+ \text { Dummies meses - } \\
\text { Estimação com Efeitos fíxos }\end{array}$ & $-8.70(*)$ & 1.3505 & 426820 \\
\hline 5) & $\begin{array}{l}\Delta i_{i, t-10} \text { cartões c/ pagamento }+ \text { Dummies meses } \\
+ \text { escore }\end{array}$ & $-7.03(*)$ & 0.418 & 439773 \\
\hline 6) & $\begin{array}{l}\Delta i_{i, t-10} \text { cartões c/ pagamento }+ \text { Dummies meses } \\
+ \text { escore }+ \text { saldo }+ \text { idade da conta }\end{array}$ & $-7.39(*)$ & 0.3538 & 432326 \\
\hline 7) & $\begin{array}{l}\Delta i_{i, t-10} \text { cartões c/ pagamento }+ \text { Dummies meses }+ \text { escore } \\
+ \text { saldo }+ \text { idade da conta }+ \text { tipo de cartão }+ \text { idade e região }\end{array}$ & $3.15(*)$ & 0.3538 & 432326 \\
\hline 8) & $\begin{array}{l}\Delta i_{i, t-10} \text { cartões c/ pagamento }+ \text { Dummies meses }+ \text { escore } \\
+ \text { saldo }+ \text { idade da conta }+ \text { idade e região }\end{array}$ & $-6.60(*)$ & 0.3540 & 432326 \\
\hline
\end{tabular}

Tabela 5 - Efeito de longo prazo dos débitos em relação à variação da taxa de juros - Diferentes especificações de estimação. (*) indica efeito de longo prazo signifincante à $5 \%$. Fonte: Elaborado pelo autor.

Uma abordagem para verificar a consistência destes resultados foi retornar as definições de defasagens e propor uma nova janela de defasagens de taxa de juros para a construção do efeito de longo prazo. Notamos que a partir de 6 defasagem da taxa de juros, os efeitos de longo prazo estimados são instáveis à medida que são incluídas mais defasagens. Em Gross e Souleles (2001a), o número de defasagens utilizadas para a estimação da relação débitos e taxa de juros foram 9 meses, menor que as 12 defasagens utilizadas na estimação da relação do limite de crédito e dos débitos. Dado estes dois pontos, reestimamos os resultados a partir da equação 2 utilizando apenas 6 defasagens da taxa de juros.

A estimação com efeitos fixos, na equação 11, pouco difere da estimação em diferenças, equação 9, proposta na metodologia. Seguiremos a análise com o equação da forma proposta na metodologia.

A partir da estimação 9, incluímos como explicativas as informações de escore, equação 12 , saldo e idade da conta, equação 13 e idade e região, equação 14 . O efeito de longo prazo estimado foi próximo de -12 nas três estimações e todos estatisticamente significante a 5\%. Porém, notem que mesmo nesta abordagem o efeito de longo prazo estimado é muito baixo se comparado ao apresentado em Gross e Souleles (2001a). 


\begin{tabular}{|c|c|c|c|c|}
\hline & & Ef. Longo Prazo & Erro Padrão & \# Obs \\
\hline 9) & $\Delta i_{i, t-6}$ cartões com pagamento + Dummies meses & $-18.97(*)$ & 0.8190 & \\
\hline 10) & $\Delta i_{i, t-6}$ cartões sem pagamento + Dummies meses & $251.36(*)$ & 7.0766 & \\
\hline 11) & $\begin{array}{l}\Delta i_{i, t-6} \text { cartões com pagamento }+ \text { Dummies meses - } \\
\text { Estimação com Efeitos fíxos }\end{array}$ & $-16.61\left(^{*}\right)$ & 0.9240 & 603198 \\
\hline 12) & $\begin{array}{l}\Delta i_{i, t-6} \text { cartões c/ pagamento }+ \text { Dummies meses } \\
+ \text { escore }\end{array}$ & $-12.53(*)$ & 0.8189 & 603198 \\
\hline 13) & $\begin{array}{l}\Delta i_{i, t-6} \text { cartões c/ pagamento }+ \text { Dummies meses } \\
+ \text { escore }+ \text { saldo }+ \text { idade da conta }\end{array}$ & $-12.19\left(^{*}\right)$ & 0.8334 & 592332 \\
\hline 14) & $\begin{array}{l}\Delta i_{i, t-6} \text { cartões c/ pagamento }+ \text { Dummies meses }+ \text { escore } \\
+ \text { saldo }+ \text { idade da conta }+ \text { idade e região }\end{array}$ & $-11.86\left(^{*}\right)$ & 0.08340 & 592332 \\
\hline 15) & $\begin{array}{l}\Delta i_{i, t-6} \text { cartões c/ pagamento }+ \text { Dummies meses }+ \text { escore } \\
+ \text { saldo }+ \text { idade da conta }+ \text { idade e região } \\
+ \text { IV: Meses desde a última alterção da tx. juros }\end{array}$ & $331.12(*)$ & 57.8642 & 592330 \\
\hline
\end{tabular}

Tabela 6 - Efeito de longo prazo dos débitos em relação à variação da taxa de juros utilizando apenas 6 defasagens da taxa de juros - Diferentes especificações de estimação. (*) indica efeito de longo prazo signifincante à $5 \%$. Fonte: Elaborado pelo autor.

Assim como nas estimações com o limite de crédito, a questão da simultaneidade pode ser uma das causas do baixo valor estimado para o efeito de longo prazo dos débitos em relação à taxa de juros. Um cliente que aumentou os débitos no cartão de crédito pode ser um cliente mais arriscado ao estar consumindo mais que sua renda poderia sustentar ou mesmo pode ser um cliente que, ao acumular débitos, está conscientemente deixando de pagar sua fatura e logo se tornará um inadimplente. Neste caso, a instituição financeira que administra o crédito disponível do cartão pode aumentar a taxa de juros, ajustando-se ao maior risco que este cliente pode representar.

Para lidarmos com a questão de simultaneidade utilizaremos a mesma abordagem da seção anterior: utilizaremos meses desde a última alteração da taxa de juros como instrumento, sendo um instrumento para cada defasagem do taxa de juros. Não utilizaremos o indicador de elegibilidade pois este está relacionado apenas a variação do limite de crédito. Poém o escore, que compõem o indicador de elegibilidade, será utilizado como um instrumento na estimação seguinte, uma vez que é variável explicativa do modelo. O efeito de longo prazo que estimamos quando incluímos variáveis instrumentais à equação é de 331, estatisticamente significante a 5\%. O resultado estimado positivo, como dito no início desta seção, é contra intuitivo à lógica pela qual esperamos que a taxa de juros afetem os débitos, descrita na seção Metodologia.

Analisando a validade dos instrumentos propostos, o teste $\mathrm{F}$ das regressões de 
cada endógena contra os instrumentos e exógenas foi sempre maior que 20 e pelo teste de Hansen, dos resíduos em relação aos instrumentos e demais exógenas obtemos a estatística $R^{2 *} \mathrm{~N}$ bem próxima de 0 . Portanto, concluímos que o resultado anterior, um valor de efeito de longo prazo positivo, não é consequência dos instrumentos que estamos utilizando para estimação.

\begin{tabular}{|c|c|}
\hline \multicolumn{2}{|c|}{ Teste F } \\
\hline \multicolumn{2}{|c|}{$\begin{array}{l}\text { H0: Parâmetros dos instrumentos } \\
\text { serem conjuntamente iguais a } 0\end{array}$} \\
\hline Endógena & F Value \\
\hline$\Delta$ Jurost $_{t}$ & 4177.74 \\
\hline$\Delta$ Juros $_{t-1}$ & 5618.89 \\
\hline$\Delta$ Juros $_{t-2}$ & 7618.12 \\
\hline$\Delta$ Juros $_{t-3}$ & 7813.03 \\
\hline$\Delta$ Juros $_{t-4}$ & 6389.3 \\
\hline$\Delta$ Juros $_{t-5}$ & 4458.28 \\
\hline$\Delta$ Juros $_{t-6}$ & 3326.15 \\
\hline
\end{tabular}

Tabela 7 - Teste F para os instrumentos. Fonte: Elaborado pelo autor.

\begin{tabular}{cr}
\hline \multicolumn{2}{c}{ Teste Hansen } \\
\hline $\begin{array}{l}\text { Regressão dos resíduos da } \\
\text { equação } 16 \text { em relação as } \\
\text { exôgenas e instrumentos }\end{array}$ \\
\hline \multicolumn{3}{c}{ R2 } & $<0.0001$ \\
No Variáveis & 40 \\
\hline
\end{tabular}

Tabela 8 - Teste de Hansen. Fonte: Elaborado pelo autor.

É possível que a elevada taxa de juros brasileira seja a causa do resultado anterior. O aumento dos juros pode levar à uma redução dos débitos que serão adquiridos a partir do momento do aumento dos juros, mas afetam os débitos já acumulados, aumentando estes, de forma que o efeito final é um aumento dos débitos do cartão. Outra explicação para o resultado anterior que é a taxa de juros não afete o comportamento de endividamento do cartonistas.

Em Lucinda e Vieira (2014), apenas o grupo da amostra com renda mais elevada mostrou-se afetado pelo aumento da taxa de juros, e mesmo para estes, o valor do impacto foi baixo, uma redução de $0,19 \%$ do total de débitos pendentes para um aumento de 1 ponto percentual da taxa de juros. Nos trabalhos de Agarwal et al. (2006) e Ponce, Seira e Zamarripa (2014) os indivíduos se mostraram pouco atentos a taxa de juros, uma vez que optaram um plano de taxa de juros e anuidade que não condiziam com seu padrão de 
consumo ou alocavam os débitos em cartões com taxa de juros mais elevado, dentre os cartões que possuiam. Além destes trabalhos, Ferman (2012) mostrou que indivíduos com mais elevado risco de crédito são menos elástico à taxa de juros impressa na fatura na hora de decidirem por financiarem o saldo da fatura do cartão.

Estes trabalhos mostram que, para países em desenvolvimento que é o caso do Brasil, mostrado em Lucinda e Vieira (2014) e Ferman (2012) e México, no caso de Ponce, Seira e Zamarripa (2014), há uma parcela de indivíduos para os quais alterações na taxa de juros não mudam o comportamento de consumo destes. Neste sentido, o efeito positivo de longo prazo estimado anteriormente pode estar carregando esta baixa elasticidade dos indivíduos à taxa de juros, uma vez que mesmo com o aumento desta, os débitos continuam positivo. Este resultado também reflete a alta taxa de juros brasileira, ou seja, mesmo que os indivíduos estejam reduzindo seus débitos, a correção ocasionada pela taxa de juros é elevada a ponto de não ser possível verificar o efeito da variação da taxa de juros nos débitos.

\subsection{Heterogeneidade dos efeitos}

Como descrito na seção Dados, os cartões da amostra são representativos dos cartões que circulam no mercado brasileiro. Portanto, é de se esperar uma heterogeneidade dos efeitos de longo prazo entre os indivíduos, que pode estar mascarado na análise agregada apresentada na seção anterior. As diferenças nas características dos cartões da amostra fica evidente na variável tipo de cartão. Conseguimos construir 4 grupos de cartões nos quais a taxa de juros, limite de crédito e saldo são diferentes. Com uma boa representatividade das quatro categorias da variável em questão, supomos que temos alguns perfis de cartonistas na amostra e que dado estes perfis, a variação do limite de crédito e da taxa de juros podem ter efeitos diferentes na variação dos débitos.

A diferença no efeito da alteração dos débitos dado uma alteração do limite é abordado em Gross e Souleles (2001a), principalmente em relação à diferença que podemos encontrar do efeito de longo prazo estimado para cartões com elevada ou baixa utilização 
do limite de crédito. O efeito de longo prazo busca mensurar o quanto do aumento do limite é utilizado como forma de crédito para a realização de compras. É possível que os cartonistas mais restritos no uso do crédito, ou seja, com menos opções de financiamento do consumo, serão os que utilizarão mais intensivamente o aumento do limite na forma de crédito. Assim, podemos supor que o efeito da variação do limite de crédito seja maior nos cartões em que a taxa de utilização do limite esteja elevada. Para os cartões que possuem limite de crédito disponível para ser utilizado como forma de financiar o consumido, o aumento do limite de crédito não deveria ocasionar um aumento significativo dos débitos.

No entanto, tal lógica é contrariada nos resultados de Gross e Souleles (2001a), que utiliza o efeito 'buffer stock' como uma explicação para um efeito de longo prazo positivo e significante dos débitos em relação à variação do limite de crédito para cartões em que a taxa de utilização do limite não é elevada. A ideia por trás do efeito 'buffer stock' propõe que os indivíduos deixam um montante de crédito disponível não comprometido, para que este sirva como fonte de financiamento caso haja algum imprevisto ao longo do tempo. Este 'colchão' de crédito aumenta quando aumentamos o limite de crédito do cartão, sendo possível liberar uma quantia do montante precaucionário para o consumo. Sendo assim, mesmos para cartões com limite de crédito disponível para ser consumido veríamos um aumento dos débitos dado um aumento do limite de crédito

Ao estimarmos o efeito de longo prazo do limite em relação aos débitos em diferentes faixas de utilização do limite de crédito tivemos que o efeito de longo prazo aumenta conforme o índice de utilização do limite de crédito torna-se maior. Além disso, mesmo em faixas de utilização do limite de crédito bem baixas, ou seja, aonde ainda há margem para aumento dos débitos sem o aumento do limite de crédito, o efeito de longo prazo estimado é positivo e significante. Este resultado é condizente com o estimado em Gross e Souleles (2001a), em que o resultado variou de 0.068 para 0.452 entre a faixa de utilização de limite mais baixa para a mais alta.

Para o efeito de longo prazo por quebras de faixa de escore de crédito, esperamos que nas faixas de escore mais elevadas, o efeito do aumento do limite de crédito seja menor que nas faixas de escore mais baixa. Isto porque, conforme dito anteriormente, o escore de 
crédito funciona como uma medida para o risco do cliente não pagar a dívida que está adquirindo com a instituição financeira. Quando mais arriscado o cliente, menores as chances de este conseguir financiamento no mercado de crédito. Assim, um cliente com escore de crédito mais baixo presumivelmente possuiria uma restrição de crédito maior que um cliente com um escore de crédito mais elevado. Então, um aumento do limite de crédito para cartões que estão na faixa de escore mais baixa deve ocasionar um efeito maior no aumento dos débitos que nas demais faixas. Para validarmos esta lógica, estimamos o efeito de longo prazo para 4 quebras de escore, cada uma contendo $25 \%$ da amostra. Para evitar que outliers distorçam a estimação, retiramos observações que estivem entre os $5 \%$ piores escore, onde há maior dispersão desta variável. O efeito de longo prazo para a subpopulação da amostra na faixa de escore de crédito mais baixa foi 0.8830 , bem maior que o efeito de longo prazo estimado para as melhores faixas de escore. Este resultado é consistente com a lógica de restrição de crédito descrita anteriormente. Vale ressaltar que mais uma vez este resultado é consistente com Gross e Souleles (2001a), porém para os dados deste trabalho, a diferença entre as populações é maior.

Por fim, analisamos o efeito de longo prazo pela quebra da variável tipo de cartão. O resultado esperado é que cartões nas faixas baixo e médio baixo tenham um efeito maior dos débitos dado uma variação do limite de crédito do que cartões classificados como médio alto e alto. Isto porque, uma vez que esta categorização está ligada com a taxa de juros, limite de crédito e renda do cartonista, esperamos que aqueles cartões com menores taxas de juros e maior limite tenham menos restrição à crédito, além de cartonistas com renda maiores poderem depender menos do mercado de crédito para o consumo e ainda assim terem maior acesso ao mercado de crédito. O resultado encontrado mais uma vez corrobora com a ideia proposta. O efeito de longo prazo estimado para cartões tipo baixo e médio baixo onde taxa de juros é mais elevada, limite de crédito mais baixo que a média e estão relacionados com faixas de renda menores, foram de 0,22 e 0.14 , ambos estatisticamente significante e maior que o estimados para as subpopulações dos cartões tipo médio alto e alto. 


\section{Ef. Longo Prazo Erro Padrão}

\begin{tabular}{|c|c|c|c|}
\hline \multicolumn{4}{|c|}{ Equação finalista para variação do limite e débitos } \\
\hline 12) & $\begin{array}{l}\Delta L_{i, t-10} \text { aut. }+ \text { Dummies meses + escore + saldo } \\
\text { idade da conta + tipo cartão + idade e região + IV: } \\
\text { Meses desde última alt. limite + Ind. Elegibilidade }\end{array}$ & $0.1144(*)$ & 0.003168 \\
\hline \multicolumn{4}{|c|}{ Índice de utilização } \\
\hline & Entre $5 \%$ e $20 \%$ & $0.0477(*)$ & 0.0042 \\
\hline & De $20 \%$ à $40 \%$ & $0.1209\left(^{*}\right)$ & 0.0055 \\
\hline & De $40 \%$ à $60 \%$ & $0.6110(*)$ & 0.0382 \\
\hline & De $60 \%$ à $80 \%$ & $0.9421(*)$ & 0.0860 \\
\hline & De $80 \%$ à $99 \%$ & $1.5583(*)$ & 0.1526 \\
\hline \multicolumn{4}{|c|}{ Faixa de escore } \\
\hline & entre 0 e $25 \%$ da distribuição (piores faixas) & $0.8830(*)$ & 0.0339 \\
\hline & de $25 \%$ a $50 \%$ & $0.0518(*)$ & 0.0117 \\
\hline & de $50 \%$ a $75 \%$ & $0.0346\left(^{*}\right)$ & 0.0080 \\
\hline & maior que $75 \%$ da distribuição (melhores faixas) & 0.0235 & * \\
\hline \multicolumn{4}{|c|}{ Tipo de cartão } \\
\hline & Baixo & 0.2278 & * \\
\hline & Médio Baixo & $0.1424(*)$ & 0.0051 \\
\hline & Médio Alto & $0.0534(*)$ & 0.0065 \\
\hline & Alto & $0.0762(*)$ & 0.0058 \\
\hline
\end{tabular}

Tabela 9 - Heterogeneidade nas estimações do efeito de longo prazo de alterações do limite nas alterações dos débitos. (*) indica efeito de longo prazo signifincante à $5 \%$. Fonte: Elaborado pelo autor. $\mathrm{O} *$ indica que não foi possível estimar a matriz de variância e covariância dos parâmetros.

As análises de heterogeneidade para a relação de limite de crédito e débitos foram realizadas a partir da equação finalista definida na subseção 5.1. Para o caso da relação de taxa de juros e débitos, o resultado final que obteve-se não atendeu o esperado, que seria uma relação de longo prazo entre débitos e taxa de juros negativa. Ao explorarmos possíveis causas para o efeito de longo prazo positivo dos débitos dado um aumento da taxa de juros, analisou-se como o efeito de longo prazo se comportaria em cada uma das categorias de tipo de cartão que temos na amostra. Como esta variável permite agregar cartões com taxa de juros e limite de crédito diferente, seria possível que a heterogeneidade da taxa de juros na amostra estivesse distorcendo o efeito de longo prazo estimado em uma única estimação. O resultado desta análise segue na tabela abaixo. 


\section{Ef. Longo Prazo Erro Padrão}

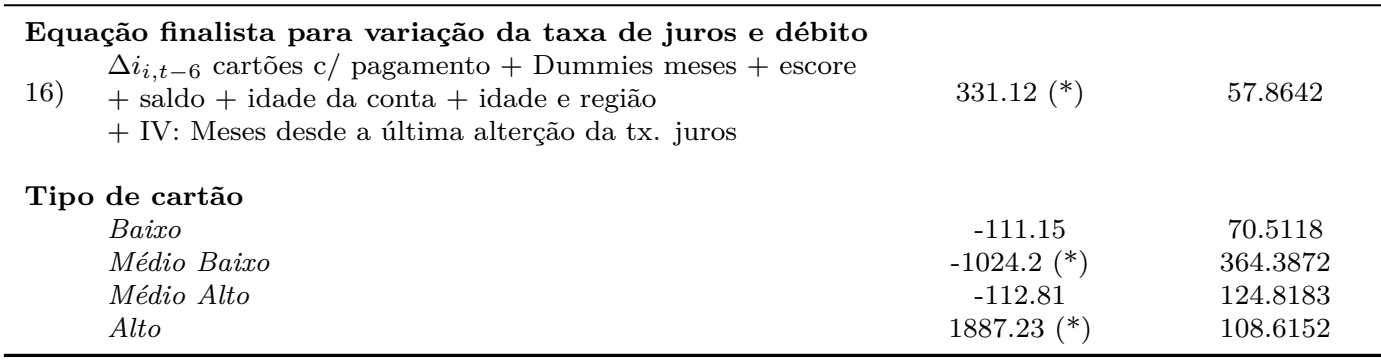

Tabela 10 - Heterogeneidade nas estimações do efeito de longo prazo de alterações da taxa de juros nas alterações dos débitos. (*) indica efeito de longo prazo signifincante à $5 \%$. Fonte: Elaborado pelo autor.

O efeito de longo prazo estimado para aqueles cartões do tipo Baixo, Médio Baixo e Médio Alto foi negativo, porém significante a $5 \%$ apenas para a estimação do tipo Médio Baixo. Este resultado é um indicativo de que é possível que a heterogeneidade da taxa de juros na amostra tenha ocasionado à estimação de um efeito de longo prazo positivo quando estimamos o efeito de longo prazo em toda a amostra. O resultado positivo para o efeito de longo prazo nos cartões do tipo Alto pode parecer estranho, uma vez que esperávamos que estes indivíduos tivessem maior acesso ao mercado de crédito e, portanto, não faz sentido manter débitos no cartão de crédito quando a taxa de juros deste aumenta. Porém, por este tipo de cartão ter a taxa de juros ser mais baixa dentre os tipos de cartão, talvez fosse necessária alterações bruscas para ocasionar redução dos débitos, como esperávamos. Ou então, como os indivíduos que possuem cartões do tipo Alto têm maior acesso ao mercado de crédito, os débitos observados nestes tipo de cartão devem ser algo ocasional e não uma real fonte de crédito.

O que podemos concluir do efeito de longo prazo estimado a partir da quebra pela variável tipo de cartão é que há uma parcela dos cartonistas, do tipo Médio Baixo, que são sensíveis à alterações da taxa de juros. Este tipo de cartão é o que possui taxa de juros um pouco acima de média e limite de crédito do cartão um pouco abaixo da média da população. É possível que esta população enfrente uma restrição de crédito maior que a parcela de cartonistas para os quais alteração a taxa de juros não implica em redução dos débitos, os classificados como Alto, os quais não parecem responder à um aumento da taxa de juros. 


\section{Conclusão}

Com os dados brasileiros, seguimos os passos de Gross e Souleles (2001a) e estimamos o efeito do limite de crédito na parcela do saldo do cartão de crédito que o cartonista deixa de pagar, ou seja, nos débitos acumulados no cartão. Para análise utilizamos apenas as faturas dos cartões em que a alteração do limite de crédito foi automática pois para aqueles que solicitaram a alteração do limite de crédito, o efeito do limite de crédito nos débitos não é a relação de causa e efeito que queremos estimar.

Obtivemos que 3,40\% da variação do limite de crédito se tornam débitos, em um horizonte de 10 meses, valor muito abaixo se comparado com o estimado por Gross e Souleles (2001a), entre 10\% e 14\%. Ao utilizarmos variáveis instrumentais na estimação, o efeito de longo prazo estimado foi 11,14\%, agora próximo do resultado de Gross e Souleles (2001a), indicando que há simultaneidade entre os dados de débitos e limite de crédito.

Este resultado nos permite concluir que assim como o mercado americano, há restrição de crédito no mercado brasileiro.

Na análise do efeito da taxa de juros sobre os débitos, estimamos o efeito de longo prazo apenas naquelas faturas com pelo menos o pagamento mínimo efetuado, e obtivemos uma redução de $\mathrm{R} \$ 11$ para uma variação de 1 ponto percentual da taxa de juros. Porém, ao tratamos a questão de simultaneidade dos dados de débitos e taxa de juros, o efeito de longo prazo estimado foi positivo, o que não era esperado e contrário a Gross e Souleles (2001a) que estima um efeito negativo da taxa de juros sobre os débitos. Os testes realizados sobre os instrumentos não indicaram haver problemas com estes.

$\mathrm{Na}$ análise de heterogeneidade, onde estimamos os efeitos de longo prazo por diferentes características da população, os resultados corroboraram com o que esperávamos encontrar. Cartões com elevado índice de utilização do limite são mais impactados pelo aumento do limite de crédito, porém, mesmo cartões com baixo índice de utilização do limite respondem a uma variação do limite de crédito. Utilizamos o efeito 'buffer stock' para explicar que o 'colchão' de crédito que os indivíduos deixam disponível para alguma emergência aumenta com o aumento do limite de crédito e, portanto, a variação do limite 
de crédito afeta os débitos mesmo em cartões com baixo índice de utilização do limite.

Cartões com baixo escore de crédito, ou seja, cartões com maiores chances de não ter o saldo tomado pago, são cartões que respondem mais fortemente a alteração da taxa de juros. Este resultado é condizente com a ideia de que os indivíduos que possuem cartões com menores escores são aqueles com menos acesso ao mercado de crédito, sendo portando o cartão aqui analisado uma fonte importante de financiamento do consumo.

Cartões do tipo baixo e médio baixo possuem um efeito de longo prazo dos débitos em relação a alteração do limite de crédito maior que os cartões do tipo médio alto e alto, que são cartões com taxa de juros menores e limite de crédito maior, o que podem representar indivíduos menos arriscados e com maior renda, ou seja, são aqueles indivíduos da amostra com menores restrição à crédito.

Por fim, estimamos o efeito de longo prazo dos débitos em relação a taxa de juros pelas quebras da variável de tipo de cartão. Encontramos que cartões do tipo médio baixo são mais sensíveis a variação da taxa de juros, reduzindo os débitos com o aumento da taxa de juros, o que é o resultado que conjecturamos que ocorreria quando descrevemos a relação entre débitos e taxa de juros. Porém, para cartões do tipo alto, o efeito de longo prazo dos débitos em relação a taxa de juros foi positivo, contra intuitivo porém explicado por este tipo de cartão pertencer aqueles indivíduos que possuem maior acesso ao mercado de crédito e logo, os débitos acumulados no cartão não devem ser uma forma de crédito permanente e sim algo eventual e uma alteração na taxa de juros não ocasionaria mudança no comportamento de consumo neste indivíduos. 


\section{Referências}

AGARWAL, S. et al. Do consumers choose the right credit contracts? Available at SSRN 943524, 2006.

AGARWAL, S. et al. Learning in the credit card market. [S.l.], 2008.

AGARWAL, S.; LIU, C.; SOULELES, N. S. The reaction of consumer spending and debt to tax rebates-evidence from consumer credit data. [S.l.], 2007.

AGARWAL, S.; QIAN, W. Consumption and debt response to unanticipated income shocks: Evidence from a natural experiment in singapore. 2013.

Associacao Brasileira das Empresas de Cartoes de Credito e Servicos. Abecs/Datafolha Mercado de Meios Eletronicos de Pagamento (Apresentacao 2013). 2014. Acessado em: 2 set. 2014. Disponível em: <http://www.abecs.org.br>.

AUSUBEL, L. M. The failure of competition in the credit card market. The American Economic Review, JSTOR, p. 50-81, 1991.

CARDHUB.COM. Credit card statistics: Number of Credit Cards and credit Card Holders. 2014. Acessado em: 2 set. 2014. Disponível em: <http://www.cardhub.com/edu/ number-of-credit-cards $/>$.

CHING, A. T.; HAYASHI, F. Payment card rewards programs and consumer payment choice. Journal of Banking $\&$ Finance, Elsevier, v. 34, n. 8, p. 1773-1787, 2010.

DEATON, A. Saving and liquidity constraints. [S.l.], 1989.

ESTADAO.COM. CNC: cartao de credito elevou endividamento das familias. 2014. Disponível em: <http://economia.estadao.com.br/noticias/geral, cnc-cartao-de-credito-elevou-endividamento-de-familias, $174830 \mathrm{e}>$.

FERMAN, B. Reading the fine print: Credit demand and information disclosure in Brazil. Tese (Doutorado) — PhD dissertation, MIT 2011. Job Market Paper, 2012.

GROSS, D. B.; SOULELES, N. S. Do liquidity constraints and interest rates matter for consumer behavior? Evidence from credit card data. [S.l.], 2001.

GROSS, D. B.; SOUlELES, N. S. An Empirical Analysis of Personal Bankruptcy and Delinquency. [S.l.], 2001.

HOCHGUERTEL, S.; WEBER, G.; ALESSIE, R. Consumer credit: evidence from italian micro data. Journal of the European Economic Association, Wiley Online Library, v. 3, n. 1, p. 144-178, 2005.

IBGE. Estimativas populacionais para os municipios brasileiros julho/2011. Disponível em: <http://www.ibge.gov.br/home/estatistica/populacao/estimativa2011/estimativa_ pop.shtm $>$.

JIANG, S. S.; DUNN, L. F. New evidence on credit card borrowing and repayment patterns. Economic Inquiry, Wiley Online Library, v. 51, n. 1, p. 394-407, 2013. 
LUCINDA, C. R. de; VIEIRA, R. L. Interest rates and informational issues in the credit market: Experimental evidence from brazil. World Development, Elsevier, v. 59, p. 47-58, 2014 .

LUDVIGSON, S. Consumption and credit: A model of time-varying liquidity constraints. The Review of Economics and Statistics, v. 81, n. 3, p. 434-447, 1999.

PONCE, A.; SEIRA, E.; ZAMARRIPA, G. Borrowing on the wrong credit card: Evidence from mexico. 2014.

SCHIAVINATTO, F.; SCHMIDT, F. de H. SIPS BANCOS: INCLUSAO FINANCEIRA E BANCARIZACAO NO BRASIL. [S.l.], 2011. P181 210.

SCHOLNICK, B. et al. The economics of credit cards, debit cards and atms: A survey and some new evidence. Journal of Banking $\&$ Finance, Elsevier, v. 32, n. 8, p. 1468-1483, 2008 .

SPRENGER, C.; STAVINS, J. Credit card debt and payment use. [S.l.], 2008.

STANGO, V. Pricing with consumer switching costs: Evidence from the credit card market. The Journal of Industrial Economics, Wiley Online Library, v. 50, n. 4, p. 475-492, 2002.

STANGO, V.; ZINMAN, J. Borrowing high vs. borrowing higher: Sources and consequences of dispersion in individual borrowing costs. [S.l.], 2013.

TELYUKOVA, I. A. Household need for liquidity and the credit card debt puzzle. The Review of Economic Studies, Oxford University Press, v. 80, n. 3, p. 1148-1177, 2013.

The Huffington Post . Cash Dying As Credit Card Payments Predicted To Grow In Volume: Report. 2014. Acessado em: 2 set. 2014. Disponível em: <http://www.huffingtonpost.com/ 2012/06/07/credit-card-payments-growth \_n\_1575417.html >.

VIGNA, S. D.; MALMENDIER, U. Contract design and self-control: Theory and evidence. The Quarterly Journal of Economics, JSTOR, p. 353-402, 2004. 